\title{
Dendritic Calcium Nonlinearities Switch the Direction of Synaptic Plasticity in Fast-Spiking Interneurons
}

\author{
Olivier Camiré and Lisa Topolnik \\ Department Biochemistry, Microbiology and Bio-informatics, Université Laval; Axis of Cellular and Molecular Neuroscience, IUSMQ, Québec, Canada
}

Postsynaptic calcium $\left(\mathrm{Ca}^{2+}\right)$ nonlinearities allow neuronal coincidence detection and site-specific plasticity. Whether such events exist in dendrites of interneurons and play a role in regulation of synaptic efficacy remains unknown. Here, we used a combination of whole-cell patch-clamp recordings and two-photon $\mathrm{Ca}^{2+}$ imaging to reveal $\mathrm{Ca}^{2+}$ nonlinearities associated with synaptic integration in dendrites of mouse hippocampal CA1 fast-spiking interneurons. Local stimulation of distal dendritic branches within stratum oriens/ alveus elicited fast $\mathrm{Ca}^{2+}$ transients, which showed a steep sigmoidal relationship to stimulus intensity. Supralinear $\mathrm{Ca}^{2+}$ events required $\mathrm{Ca}^{2+}$ entry through AMPA receptors with a subsequent $\mathrm{Ca}^{2+}$ release from internal stores. To investigate the functional significance of supralinear $\mathrm{Ca}^{2+}$ signals, we examined activity-dependent fluctuations in transmission efficacy triggered by $\mathrm{Ca}^{2+}$ signals of different amplitudes at excitatory synapses of interneurons. Subthreshold theta-burst stimulation (TBS) produced small amplitude postsynaptic $\mathrm{Ca}^{2+}$ transients and triggered long-term potentiation. In contrast, the suprathreshold TBS, which was associated with the generation of supralinear $\mathrm{Ca}^{2+}$ events, triggered long-term depression. Blocking group I/II metabotropic glutamate receptors (mGluRs) during suprathreshold TBS resulted in a slight reduction of supralinear $\mathrm{Ca}^{2+}$ events and induction of short-term depression. In contrast, blocking internal stores and supralinear $\mathrm{Ca}^{2+}$ signals during suprathreshold TBS switched the direction of plasticity from depression back to potentiation. These data reveal a novel type of supralinear $\mathrm{Ca}^{2+}$ events at synapses lacking the GluA2 AMPA subtype of glutamate receptors and demonstrate a general mechanism by which $\mathrm{Ca}^{2+}$-permeable AMPA receptors, together with internal stores and mGluRs, control the direction of plasticity at interneuron excitatory synapses.

Key words: calcium; dendrite; interneuron; intracellular release; plasticity; synapse

\section{Introduction}

Hebb's learning rule requires a tight temporal association of input and output at activated synapses. The backpropagating action potential (AP) informs the dendrites about the occurrence of neuronal output and provides the critical level of membrane depolarization necessary for the activation of voltage-dependent $\mathrm{Ca}^{2+}$ mechanisms and generation of supralinear $\mathrm{Ca}^{2+}$ signals (Magee and Johnston, 1997). However, in most inhibitory interneurons, AP backpropagation is largely attenuated with distance from the soma because of the nonuniform distribution of voltage-gated ion conductances (Goldberg et al., 2003a; Hu et al., 2010; Evstratova et al., 2011). As a result, backpropagating APs can generate significant $\mathrm{Ca}^{2+}$ elevations and, accordingly, control the induction of Hebbian forms of plasticity only at synapses located proximally. Local upregulation of $\mathrm{AP}$-evoked $\mathrm{Ca}^{2+}$ tran-

\footnotetext{
Received May 27, 2013; revised Jan. 9, 2014; accepted Feb. 4, 2014.

Author contributions: L.T. designed research; 0 .C. and L.T. performed research; 0 .C. and L.T. analyzed data; $0 . C$. and L.T. wrote the paper.

This work was supported by the Canadian Institute of Health Research, the Natural Sciences and Engineering Research Council of Canada (NSERC), and the Savoy Foundation. 0.C. was supported by the NSERC PhD fellowship. L.T. is the recipient of the NSERC Faculty Award for Women. We thank Dimitry Kullmann and Marco Capogna for stimulating discussions and comments on the previous version of this manuscript, and Dimitry Topolnik for excellent technical assistance.

Correspondence should be addressed to Lisa Topolnik, Axis of Cellular and Molecular Neuroscience, $2601 \mathrm{Ch}$. De La Canardière, CRULRG, Québec, PQ, G1J 2G3, Canada. E-mail: Lisa.Topolnik@crulrg.ulaval.ca.

DOI:10.1523/JNEUROSCI.2253-13.2014

Copyright $\odot 2014$ the authors $\quad 0270-6474 / 14 / 343864-14 \$ 15.00 / 0$
}

sients by changes in synaptic activity can rescue the induction of Hebbian plasticity at interneuron excitatory synapses (Topolnik et al., 2009). Alternatively, the induction of associative plasticity at distal synapses may rely on local regenerative activity. Studies on pyramidal neurons revealed dendritic $\mathrm{Ca}^{2+}$ spikes initiated via activation of NMDA receptors (NMDARs) and voltage-gated $\mathrm{Ca}^{2+}$ channels (VGCCs) as a mechanism for coincidence detection at distal synapses (Regehr and Tank, 1990; Markram and Sakmann, 1994; Schiller et al., 1997; Golding et al., 2002; Losonczy and Magee, 2006; Remy and Spruston, 2007; Tsay et al., 2007). In addition, pyramidal neurons exhibit dendritic $\mathrm{Ca}^{2+}$ nonlinearities in the form of $\mathrm{Ca}^{2+}$ waves resulting from the activation of metabotropic glutamate receptors (mGluRs) and a subsequent $\mathrm{Ca}^{2+}$ release from internal stores (Wang et al., 2000; Nakamura et al., 2002; Watanabe et al., 2006). In interneurons, the mechanisms of dendritic regenerative activity remain largely unknown, although dendritic $\mathrm{Ca}^{2+}$ spikes have been reported in neocortical low threshold spiking cells and hippocampal CA1 stratum radiatum interneurons (Goldberg et al., 2004; Katona et al., 2011). In particular, it remains unclear how different patterns of synaptic activity can take part in the initiation of dendritic regenerative signals and how these events can regulate the efficacy of transmission at distal synapses.

Here, we used a combination of whole-cell patch-clamp recordings and two-photon $\mathrm{Ca}^{2+}$ imaging in the distal dendritic branches of mouse hippocampal CA1 fast-spiking (FS) cells to 
explore the mechanisms and functional relevance of $\mathrm{Ca}^{2+}$ nonlinearities evoked by the activation of glutamatergic synapses. In marked contrast to previously described mechanisms, synaptically evoked $\mathrm{Ca}^{2+}$ nonlinearities in FS interneurons involved primarily the activation of GluA2-lacking AMPA receptors with a subsequent $\mathrm{Ca}^{2+}$ release, were highly localized within individual dendritic branches and switched the direction of plasticity from long-term potentiation (LTP) to short-term depression (STD) or long-term depression (LTD), with the duration of depression depending on the additional recruitment of the group I/II mGluRs.

\section{Materials and Methods}

Slice preparation and patch-clamp recordings. Hippocampal slices (300 $\mu \mathrm{m})$ were prepared from CD1 mice of either sex (P13-P21) as described previously (Evstratova et al., 2011) in accordance with the animal welfare guidelines of the Université Laval. During experiments, slices were perfused with standard artificial CSF (ACSF) containing the following (in mM): $124 \mathrm{NaCl}, 2.5 \mathrm{KCl}, 1.25 \mathrm{NaH}_{2} \mathrm{PO}_{4}, 26 \mathrm{NaHCO}_{3}, 2 \mathrm{MgSO}_{4}, 2 \mathrm{CaCl}_{2}$, and 10 glucose saturated with $95 \% \mathrm{O}_{2}$ and $5 \% \mathrm{CO}_{2}, \mathrm{pH} 7.4$, at $30-33^{\circ} \mathrm{C}$. In all experiments, GABAergic transmission was blocked by the GABAA and GABAB receptor antagonists gabazine $(1 \mu \mathrm{M})$ and CGP55845 (2 $\mu \mathrm{M})$, respectively. In some experiments, DL-AP5 (100 $\mu \mathrm{M})$, 1-naphthyl acetyl spermine (NASPM; 3-60 $\mu \mathrm{M}$ ), philanthotoxin 433 (PhTx, $1 \mu \mathrm{M})$, NBQX $(10 \mu \mathrm{M}), d$-tubocurarine $(d \mathrm{TC} ; 20 \mu \mathrm{M})$, nifedipine $(10 \mu \mathrm{M}), \mathrm{NNC}$ 55-0396 (10 $\mu \mathrm{M}), \mathrm{Ni}^{2+}(50 \mu \mathrm{M}), \mathrm{CPA}(30 \mu \mathrm{M})$, ryanodine $(30 \mu \mathrm{M})$, SNX-482 $(30 \mathrm{nM})$, or E4CPG $(500 \mu \mathrm{M})$ were included in the ACSF and caffeine (1 mM) was puff applied (50 ms). As NASPM, PhTx, and nifedipine are use-dependent blockers (Koike et al., 1997; Tóth and McBain, 1998; Shen et al., 2000), the following procedure was applied when using these pharmacological agents: after an initial period of recording of control responses, the slice was incubated in a solution containing the blocker for $10 \mathrm{~min}$. After this period, synaptic stimulation was resumed, and the current amplitude as well as the peak $\mathrm{Ca}^{2+}$ transient were blocked in a use-dependent manner during the next $20 \mathrm{~min}$.

Whole-cell patch-clamp recordings were obtained from interneurons located in the CA1 stratum oriens adjacent to the stratum pyramidale, which were identified using a $40 \times$ water-immersion objective and infrared differential interference contrast (IR-DIC) microscopy. Recording pipettes (3-6 M $\Omega$ ) were made from borosilicate glass capillaries (1B100F-4; World Precision Instruments). For whole-cell current-clamp recordings, the pipette solution contained the following (in $\mathrm{mM}$ ): 130 $\mathrm{KMeSO}_{3}, 2 \mathrm{MgCl}_{2}, 10$ diNa-phosphocreatine, 10 HEPES, 2-4 ATP-Tris, 0.2 GTP-Tris, $0.2-0.3 \%$ biocytin, and $\mathrm{Ca}^{2+}$-insensitive (Alexa Fluor 594, $20 \mu \mathrm{M}$; Invitrogen) and $\mathrm{Ca}^{2+}$-sensitive [Fluo-5F, $300 \mu \mathrm{M}$ or Oregon Green BAPTA 5N (OGB-5N), $500 \mu \mathrm{M}$; Invitrogen] dyes, pH 7.2-7.3, 275-290 mOsmol/L. In some experiments, spermine $(100 \mu \mathrm{M})$ or QX$314(2-5 \mathrm{~mm})$ was included in the intracellular solution.

Two-photon $\mathrm{Ca}^{2+}$ imaging. Dendritic $\mathrm{Ca}^{2+}$ imaging was performed using a TCS SP5 two-photon laser-scanning microscope (Leica Microsystems) based on a Ti-sapphire laser (Chameleon Ultra II; Coherent; >3 $\mathrm{W}, 140 \mathrm{fs}$ pulses, $80 \mathrm{~Hz}$ repetition rate) tuned to $800 \mathrm{~nm}$. A long-range water-immersion objective ( $40 \times$; NA 0.8$)$ was used to collect photons in the epifluorescence mode with external photomultiplier tubes. Neurons were filled with indicators via the patch electrode for 20-30 min before imaging. Red fluorescence from Alexa Fluor 594 was used to locate dendrites of interest. To measure $\mathrm{Ca}^{2+}$ signals, green and red fluorescence was collected during $500 \mathrm{~Hz}$ line scans along or across dendritic segments of 2-15 $\mu \mathrm{m}$. Fluorescence changes were quantified as increases in green fluorescence from the baseline normalized to the red fluorescence: $\Delta G / R=(G-G 0) / R$ or as changes in green fluorescence from the baseline $\Delta F / F=(F-F 0) / F 0$.

Synaptic stimulation and plasticity induction. To study the rules of synaptic integration in dendrites of interneurons, we took advantage of physiological synaptic stimulation using a local bipolar microelectrode. Although two-photon glutamate uncaging allows for the temporally precise activation of a defined number of synaptic inputs in pyramidal cells, it can produce undesirable effects (activation of perisynaptic and extra- synaptic receptors) in aspiny dendrites of interneurons. Local activation of distal synaptic inputs (80-200 $\mu \mathrm{m}$ from the soma) in the stratum oriens/alveus was achieved using a bipolar stimulating electrode made from the borosilicate theta-glass capillaries (BT-150-10; Sutter Instruments) and filled with ACSF containing 5-10 $\mu \mathrm{M}$ Alexa Fluor 594. The electrode was positioned 7-20 $\mu \mathrm{m}$ from the dendritic branch of interest under visual control (Figs. $1 A, 7 C$ ) and connected to a constant current isolation unit (A360LA; World Precision Instruments). Dendritic $\mathrm{Ca}^{2+}$ transients and corresponding somatic responses were evoked by brief bursts of synaptic stimulation (three stimuli at $100 \mathrm{~Hz}, 0.1 \mathrm{~ms}$ each) of various intensities applied once every $30 \mathrm{~s}$. The threshold stimulation was defined as the minimal intensity of stimulation necessary to evoke postsynaptic responses. The stimulus strength was then increased gradually with a step of $10-15 \%$ up to $200 \%$ of the threshold and both somatic and dendritic responses were recorded. In 31 of 40 cells examined, a 10$100 \%$ increase in stimulus intensity from the threshold resulted in a supralinear dendritic $\mathrm{Ca}^{2+}$ event (Fig. 2), which was associated with a generation of 2-4 APs in the soma.

In synaptic plasticity experiments, the pipette solution had the same composition as in $\mathrm{Ca}^{2+}$ imaging experiments, except for adding spermine $(100 \mu \mathrm{M})$ and omitting the $\mathrm{Ca}^{2+}$ indicator. The plasticity induction protocol was applied within $8 \mathrm{~min}$ of whole-cell recording to avoid extensive dendritic washout. Similar to $\mathrm{Ca}^{2+}$ imaging experiments, the stimulating electrode was filled with ACSF containing $5 \mu \mathrm{M}$ Alexa Fluor 594 and positioned 7-20 $\mu \mathrm{m}$ from the distal dendritic branch under visual guidance. Voltage-clamp recordings of baseline EPSCs were performed for $3 \mathrm{~min}$ at a subthreshold (for somatic AP initiation) level of stimulation. In one series of experiments (Fig. 8B), three theta-burst trains of stimuli (TBS: 3 pulses $/ 100 \mathrm{~Hz}$ repeated eight times at $4 \mathrm{~Hz}$ for $2 \mathrm{~s}$ ) of the same baseline intensity were applied at $30 \mathrm{~s}$ intervals to the cell recorded in current-clamp mode at $-70 \mathrm{mV}$. This induction paradigm was defined as subthreshold TBS. Thereafter, voltage-clamp recordings of EPSCs were resumed for a further 20-30 min. To mimic the conditions necessary for the generation of dendritic $\mathrm{Ca}^{2+}$ nonlinearities, in the second series of experiments (Fig. $8 C-E$ ), the stimulation intensity during TBS was raised to $200 \%$ (to ensure the induction of supralinear $\mathrm{Ca}^{2+}$ events). Accordingly, such induction paradigm was defined as suprathreshold TBS. Thereafter, the stimulation intensity was reduced to the baseline level and voltage-clamp recordings of EPSCs were resumed.

To obtain the $I-V$ relationship of EPSCs, cells were recorded in a voltage-clamp configuration using a $\mathrm{Cs}^{+}$-based internal solution containing spermine $(100 \mu \mathrm{M})$ and QX-314 $(2-5 \mathrm{~mm})$ and EPSCs were evoked by single stimuli at different levels of membrane potential (from -80 to $+60 \mathrm{mV}$ with a step of $20 \mathrm{mV}$, liquid junction potential not corrected).

Data acquisition and analysis. Data acquisition (filtered at $2-3 \mathrm{kHz}$, digitized at $10 \mathrm{kHz}$ ) was performed using Clampex 10.2 and analyzed using Clampfit 10.2 (Molecular Devices), Leica LAS, Igor Pro (WaveMetrics), and Excel (Microsoft). Series resistance was 10-25 M $\Omega$. Pipette capacitance and series resistance (or bridge balance in current-clamp experiments) were compensated. Series resistance was verified every 5 min and readjusted if necessary. Cells with resting membrane potentials more positive than $-50 \mathrm{mV}$, fluctuations in holding current, or unstable series resistance were discarded. In current-clamp experiments, interneurons were held at $\sim-70 \mathrm{mV}$ by injecting current $(-20$ to $-50 \mathrm{pA})$, if necessary.

To measure $\Delta G / R$ peak amplitude, we averaged the values around the peak over a $10 \mathrm{~ms}$ time window. In summation experiments, both $\Delta G / R$ peak amplitude and the stimulus intensity were normalized to their threshold values (the minimal intensity necessary to evoke the minimal $\mathrm{Ca}^{2+}$ response). In the experiments illustrated in Figure 5, the $\mathrm{Ca}^{2+}$ nonlinearity threshold was determined as the minimal stimulus intensity necessary to evoke a supralinear $\mathrm{Ca}^{2+}$ event. In these experiments, subthreshold $\Delta G / R$ amplitude was determined as the $\Delta G / R$ peak amplitude associated with a subthreshold (for AP generation) somatic response. Spontaneous EPSCs (sEPSCs) were analyzed using the search events algorithm of Clampfit 10.2. Only those events that were not contaminated by ambiguous deflections at their rising or decaying phases, and decayed back to the baseline, were selected for the analysis of kinetics. All events 
were counted for frequency analysis. Typically, 200 events per cell were chosen. sEPSC amplitudes were measured at the peak of the waveform. The rise time was defined as the duration of $20-80 \%$ of the sEPSC peak amplitude. The decay phase of the sEPSCs was fitted with a single exponential. Summary data are shown as means \pm SEM. Significance between groups was assessed using the paired $t$ test, the Mann-Whitney test, or one-way ANOVA at $p<0.05$.

Morphological and neurochemical identification of interneurons. For anatomical reconstruction, neurons were filled with biocytin (Sigma) during whole-cell recordings. Slices with recorded cells were fixed overnight with $4 \%$ paraformaldehyde (PFA) at $4^{\circ} \mathrm{C}$. To reveal biocytin, slices were permeabilized with 1.5-3\% Triton X-100 and incubated overnight at $4^{\circ} \mathrm{C}$ with streptavidin-conjugated Alexa Fluor 546 or 488 (1:200; Jackson ImmunoResearch). Sections were mounted in Dako fluorescence medium and confocal images of biocytin-filled interneurons were obtained using a Leica TCS SP5 imaging system coupled with $543 \mathrm{~nm} \mathrm{He}-\mathrm{Ne}$ and $488 \mathrm{~nm}$ Argon lasers. Interneuron $Z$ stacks were acquired using a $1 \mu \mathrm{m}$ step. Anatomical reconstruction was performed using the Neurolucida 8.26.2 software (MBF Bioscience). The morphological identification of recorded interneurons was achieved by the analysis of their axonal arborization.

For neurochemical identification, slices with recorded neurons were fixed with 4\% PFA and re-sectioned (thickness, $50 \mu \mathrm{m}$ ) using a Leica VT1000 vibratome (Leica Microsystems). Sections were permeabilized with $0.3 \%$ Triton X-100 in TBS and incubated in blocking solution containing 4\% bovine serum albumin and 10\% normal serum for $1 \mathrm{~h}$. After this step, sections were incubated with streptavidin-conjugated Alexa Fluor 546 (1:200; Jackson ImmunoResearch) to reveal biocytin and a mouse monoclonal anti-parvalbumin antibody (P3088; Sigma) at $4^{\circ} \mathrm{C}$ for $24 \mathrm{~h}$. The following day, slices were incubated with an anti-mouse secondary antibody (DyLight-647; Jackson ImmunoResearch) for 2-4 h, rinsed, and mounted on microscope slides. Confocal images of labeled processes were obtained using a Leica TCS SP5 imaging system and a $63 \times$ (NA 1.4) oil-immersion objective (Leica Microsystems).

\section{Results}

\section{Postsynaptic $\mathrm{Ca}^{2+}$ mechanisms in distal dendrites of hippocampal CA1 FS interneurons}

We performed whole-cell patch-clamp recordings from hippocampal CA1 FS interneurons tentatively identified based on their morphological properties in the IR-DIC image: largediameter fusiform cell body located within the stratum oriens adjacent to the stratum pyramidale. Only cells that exhibited nonaccommodating FS firing pattern [with an average frequency of $207.7 \pm 7.8 \mathrm{~Hz}\left(\right.$ at $\left.30-33^{\circ} \mathrm{C}\right)$ in response to a $1 \mathrm{~s} 1 \mathrm{nA}$ current pulse; $n=84$; Figure $1 B]$ were included in this study. All recorded interneurons were filled with biocytin for post hoc anatomical and neurochemical identification (Fig. 1C). Among 84 FS cells recorded, 61 neurons were labeled successfully and reconstructed. Based on anatomical criteria, 25 recorded neurons were identified as basket cells (BCs; Fig. 1C, top left) and 30 neurons were identified as bistratified cells (BISs; Fig. 1C, top right). A subset of recorded cells was processed for parvalbumin (PV) immunoreactivity. As our typical $\mathrm{Ca}^{2+}$ imaging experiment lasted for at least $1 \mathrm{~h}$, we were only able to detect PV expression in neuronal processes (distal dendrites and axonal branches) due to a rapid washout of cytoplasmic $\mathrm{Ca}^{2+}$ buffers from perisomatic compartments during whole-cell recordings (Müller et al., 2005). Nevertheless, seven of seven examined neurons revealed PV immunoreactivity in axonal branches (Fig. 1C, bottom). Consistent with previous findings (Sik et al., 1995; Buhl et al., 1996; Ali et al., 1998; Glickfeld and Scanziani, 2006), FS interneurons recorded here had a resting membrane potential of $-63.6 \pm 0.9$ $\mathrm{mV}$, input resistance of $99.3 \pm 6.1 \mathrm{M} \Omega$ and a membrane time constant of $9.9 \pm 0.5 \mathrm{~ms}(n=55)$. Furthermore, as reported previously (Buhl et al., 1996), BCs exhibited a significantly lower input resistance and faster time constant when compared with BISs [BC: $R_{i n}=84.4 \pm 7.1 \mathrm{M} \Omega, \tau=8.4 \pm 0.4 \mathrm{~ms}, n=25$; BISs: $R_{i n}=114.2 \pm 5.1 \mathrm{M} \Omega, \tau=11.5 \pm 0.5 \mathrm{~ms}, n=31 ; p<0.05$; Mann-Whitney test].

Because in many types of interneurons dendritic $\mathrm{Ca}^{2+}$ transients evoked by backpropagating APs (bAP-CaTs) decline with distance from the soma, we first examined the spatial profile of bAP-CaTs in CA1 FS interneurons. Cells were loaded with a medium-affinity $\mathrm{Ca}^{2+}$ indicator (Fluo-5F) and a $\mathrm{Ca}^{2+}$ insensitive morphological dye (Alexa Fluor 594) for 20-30 min (Fig. 1A). After the loading period, small trains of APs were initiated by somatic current injection $(0.8-1 \mathrm{nA}, 2 \mathrm{~ms} ; 10$ APs at 100 $\mathrm{Hz}$ ) and corresponding bAP-CaTs were examined in dendritic shafts at different distances from the cell body (Fig. 1A, white lines). Consistent with previous findings in cortical FS interneurons (Goldberg et al., 2003a) and dentate gyrus BCs (Aponte et al., 2008), bAP-CaTs in CA1 FS interneurons were highly restricted within proximal dendritic sites (Fig. 1D).

To determine the sources of postsynaptic $\mathrm{Ca}^{2+}$ elevations that may operate in distal dendritic branches $(80-200 \mu \mathrm{m}$ from the soma), a theta-glass bipolar stimulating electrode was positioned at 7-20 $\mu \mathrm{m}$ from the branch of interest within the stratum oriens/ alveus (Figs. $1 A, 7 C, 8 A$ ). Therefore, excitatory responses analyzed in this study were evoked primarily by the activation of local CA1 pyramidal cell (PC) input (Takács et al., 2012). First, to examine the presence of NMDARs at these synapses, EPSCs were evoked by single shocks (15-50 $\mu \mathrm{A}, 0.1 \mathrm{~ms}$; Fig. $1 E)$ in low $\mathrm{Mg}^{2+}$ (0.5 mM) ACSF. Surprisingly, in 6 of 11 interneurons, EPSCs evoked in such conditions showed a strong inward rectification [Rectification Index $(R I)=0.11 \pm 0.04$; Figure $1 E$, black traces and symbols], consistent with the major role of GluA2-lacking $\mathrm{Ca}^{2+}$-permeable AMPA receptors (CP-AMPARs) and with the absence of NMDAR component at these synapses. The remaining cells exhibited a mixed contribution from CP-AMPARs and NMDARs, as their EPSCs showed two components: one with a linear $I-V$ relationship, which was sensitive to the NMDAR antagonist DL-AP5 (Fig. 1E, red traces and symbols), and the second, which exhibited a strong inward rectification $(R I=0.17 \pm$ 0.02 ), with insensitivity to DL-AP5. Furthermore, in all cells examined, EPSCs were sensitive to NASPM (Fig. $1 F$ ), a synthetic analog of the Joro spider toxin, which is a selective inhibitor of CP-AMPARs (Koike et al., 1997). Importantly, CP-AMPARdominating synapses with variable contribution from NMDARs (range: $0-45 \%$ ) were observed in both BCs and BISs. Moreover, when NMDARs were present, we found no significant difference in the ratio of the CP-AMPAR to NMDAR EPSC components between the two cell types (BCs: $1.7 \pm 0.04, n=4$; BISs: $1.8 \pm$ $0.06, n=4, p>0.05$, Mann-Whitney test). Thus, for the rest of the study, the data obtained from BCs and BISs were pooled together.

To examine the relative contribution of NMDARs versus CPAMPARs at these synapses under more physiological conditions, we studied their role in synaptically evoked $\mathrm{Ca}^{2+}$ elevations in normal ACSF $\left(\mathrm{Mg}^{2+}, 2 \mathrm{mM}\right)$. Interneurons were filled with a low-affinity $\mathrm{Ca}^{2+}$ indicator (OGB-5N) and a morphological dye Alexa Fluor 594, and postsynaptic $\mathrm{Ca}^{2+}$ transients were evoked by a brief burst of synaptic stimulation (three pulses at $100 \mathrm{~Hz}$ ) at $-70 \mathrm{mV}$ (Fig. 1G). Under these conditions, local subthreshold (for somatic AP initiation) synaptic stimulation produced fast $\mathrm{Ca}^{2+}$ transients (decay time constant: $63.3 \pm 11.2 \mathrm{~ms}, n=6$; Figs. $1 G, 2 A, 5 A)$ that were highly localized within dendritic microdomains ( $6.0 \pm 0.9 \mu \mathrm{m}, n=6$; Figs. $1 G, 7 B)$, consistent with previous findings in aspiny dendrites of cortical FS interneurons 
A

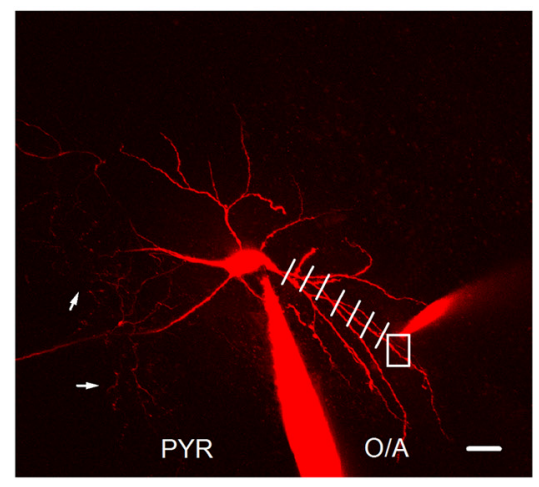

D1
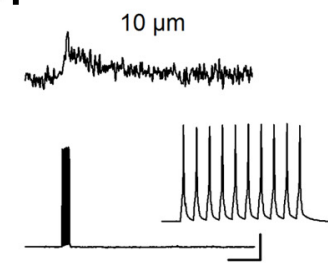

E

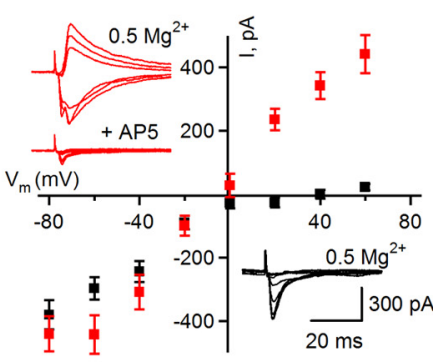

F
B

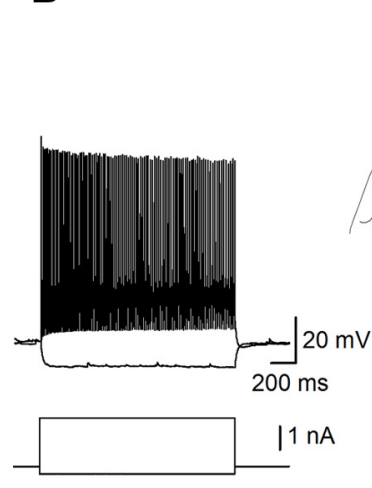

C

BC
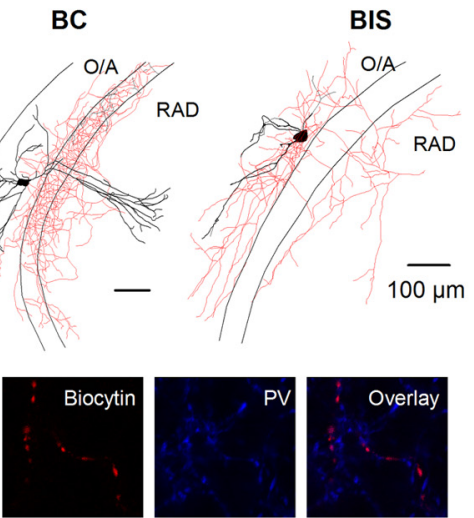

D2

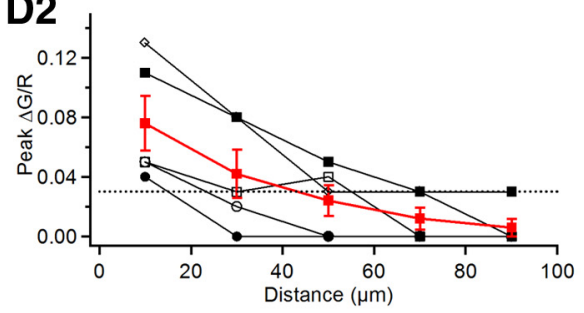
$=00 \mathrm{~ms}$

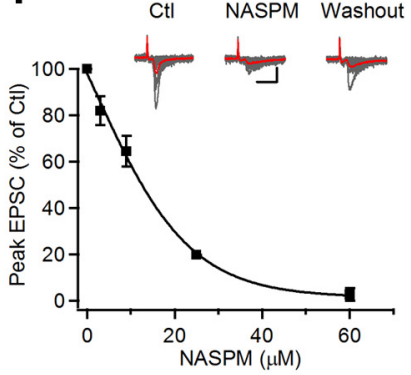

G

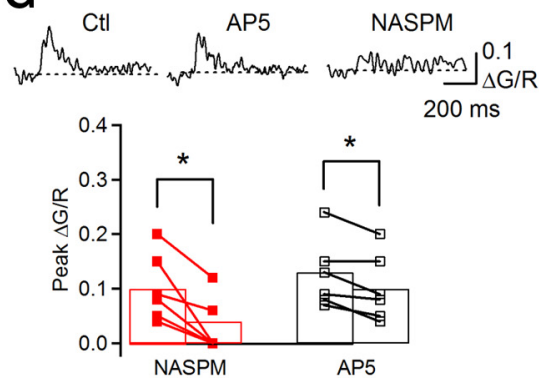

Figure 1. Postsynaptic $\mathrm{Ca}^{2+}$ mechanisms in distal dendrites of hippocampal CA1 FS interneurons. A, Two-photon image (maximal projection) of an interneuron filled with Alexa Fluor 594 and $0 G B-5 N$. White arrows indicate the axon. White lines point to locations where bAP-CaTs were measured. White square indicates the dendritic area where postsynaptic $\mathrm{Ca}^{2+}$ signals were detected. Scale bar, $100 \mu \mathrm{m}$. B, Firing pattern of a typical FS interneuron. C, Neurolucida reconstructions of a BC and of a BIS (axon indicated in red; top) and confocal images of an axonal terminal labeled with biocytin (left) and immunoreactive for PV (middle), with an overlay of both images (right). $\boldsymbol{D}$, Representative examples of bAP-CaTs (D1) evoked by a train of 10 APs at different distances from the soma. The summary plot (D2) shows the decrease in amplitude of bAP-CaTs relative to the distance from the soma. Data from individual cells are shown in black; average data are shown in red. The dotted line indicates the threshold level below which the signal was indistinguishable from noise. E, Summary plot of the I-V relationship of EPSCs evoked at distal synapses. EPSCS were recorded at different levels of membrane potential ( -80 to $60 \mathrm{mV})$ in $0.5 \mathrm{~mm} \mathrm{Mg}{ }^{2+}$ ACSF and in the presence of NMDAR antagonist DL-AP5 (100 $\left.\mu \mathrm{m}\right)$. Insets show representative examples of the two types of synaptic responses identified with (red traces) or without (black traces) the NMDAR component. Summary plots include data obtained in BCs and BISs. F, Summary dose-response plot showing EPSC sensitivity to NASPM. Inset, Examples of EPSCs recorded in the control condition (normal ACSF, left), in the presence of NASPM (25 $\mu$ m; middle), and following its washout (right). Red trace represents the average. $\mathbf{G}$, Representative examples of postsynaptic $\mathrm{Ca}^{2+}$ signals evoked by subthreshold synaptic stimulation in the control condition (left) and in the presence of $\mathrm{DL}-\mathrm{AP5}$ (middle) and NASPM (right). The summary data underneath show changes in the peak amplitude of postsynaptic $\mathrm{Ca}^{2+}$ signals in the presence of DL-AP-5 (black symbols) or NASPM (red symbols). 0/A, Oriens/alveus; PYR, stratum pyramidale; RAD, stratum radiatum.

(Goldberg et al., 2003b). Furthermore, the application of the NMDAR antagonist DL-AP5 slightly reduced the postsynaptic $\mathrm{Ca}^{2+}$ transients at some synapses and had no effect at others (Fig. $1 G)$, which is in line with a variable contribution of NMDARs at these synapses. When put together, these results revealed a small but significant decrease of postsynaptic $\mathrm{Ca}^{2+}$ transients in the presence of DL-AP5 (to $77.1 \pm 7.1 \%$ of control; $n=6$; Fig. $1 G$ ), indicating that NMDARs make a minor contribution to postsynaptic $\mathrm{Ca}^{2+}$ influx at local CA1 synapses onto FS interneurons under physiological conditions. In contrast, postsynaptic $\mathrm{Ca}^{2+}$ transients exhibited a greater sensitivity to the CP-AMPAR inhibitor NASPM (decrease to $21.6 \pm 9.9 \%$ of control; $n=7$; Fig. $1 G$ ), which was also successful in blocking the residual DL-AP-5resistant component of subthreshold postsynaptic $\mathrm{Ca}^{2+}$ transients $(n=6$; Fig. $1 G)$. Together, our data indicate that it is CP-AMPARs, not NMDARs, that provide the major contribu- tion to postsynaptic $\mathrm{Ca}^{2+}$ signals at CA1 local collateral synapses on FS interneurons.

\section{Dendritic $\mathrm{Ca}^{2+}$ nonlinearities in FS interneurons}

Previous studies in CA1 pyramidal cells showed that burst stimulation of distal synapses elicits local dendritic $\mathrm{Ca}^{2+}$ spikes (Golding et al., 2002; Tsay et al., 2007). To determine whether any type of local regenerative activity can be initiated synaptically in dendrites of FS cells, we examined the summation of postsynaptic $\mathrm{Ca}^{2+}$ transients during synaptic stimulation of increasing intensity using a low-affinity $\mathrm{Ca}^{2+}$ dye (OGB-5N; Fig. 2). Similar to findings in pyramidal cells (Golding et al., 2002; Tsay et al., 2007), distal $\mathrm{Ca}^{2+}$ signals in interneurons exhibited a steep sigmoidal relationship to stimulus intensity (Fig. $2 A, B$ ), consistent with the generation of nonlinear regenerative responses. At low stimulus intensities, subthreshold for somatic AP generation, postsynaptic 
A
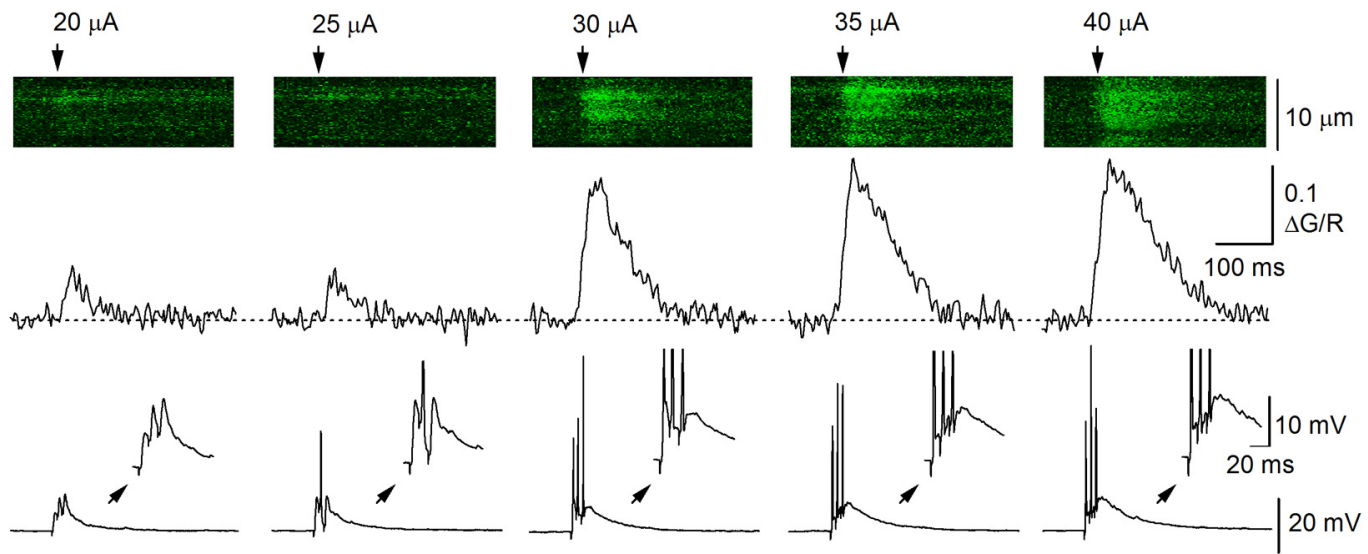

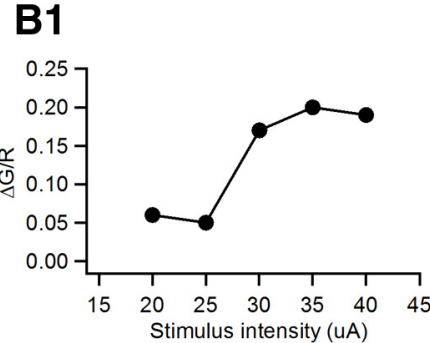

D

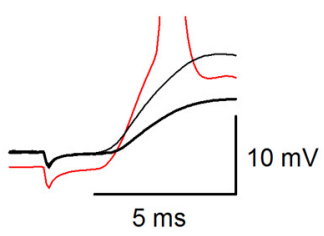

\section{B2}

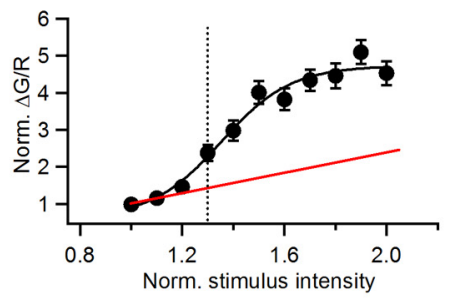

E

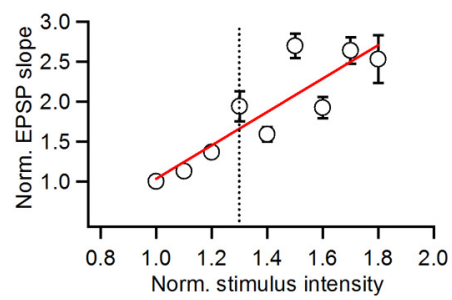

C $\quad 25 \mu \mathrm{A}$

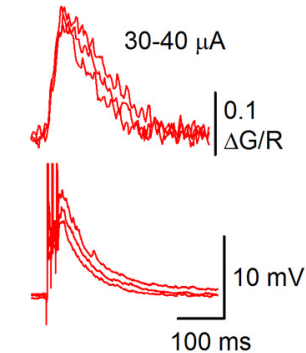

$\mathbf{F}$

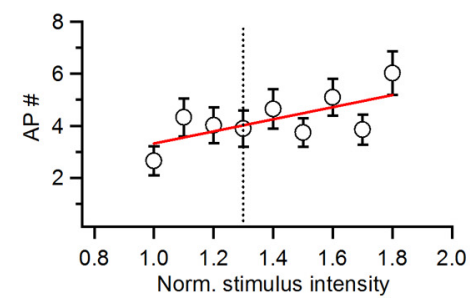

Figure 2. Supralinear $\mathrm{Ca}^{2+}$ signals in distal dendrites of $\mathrm{FS}$ interneurons. $\boldsymbol{A}$, Line scan images (top) with corresponding postsynaptic $\mathrm{Ca}^{2+}$ transients and voltage responses evoked by synaptic stimulation of varying intensity. Black arrowheads on top indicate the onset of synaptic stimulation. Insets, Expanded view of the somatic voltage responses (with APs truncated). $\boldsymbol{B}$, Representative example (B1) and summary plot (B2) of $\mathrm{Ca}^{2+}$ transient peak amplitude versus stimulus intensity. Red line shows the linear fit between the first three values. Dotted line indicates the $\mathrm{Ca}^{2+}$ nonlinearity threshold. $\boldsymbol{C}$, Representative somatic responses before (black) and during the induction of supralinear $\mathrm{Ca}^{2+}$ events (red). $\boldsymbol{D}$, Representative examples of the somatic response to gradually increasing stimulation (red trace corresponds to supralinear $\mathrm{Ca}^{2+}$ event). $\boldsymbol{E}, \boldsymbol{F}$, Summary plots showing the normalized EPSP slope $(\boldsymbol{E})$ and the number of APs $(\boldsymbol{F})$ versus the stimulus intensity (dotted lines indicate the $\mathrm{Ca}^{2+}$ nonlinearity threshold). Red lines show the linear fits. Note that both EPSP slope and AP number show a gradual increase in response to increasing stimulus intensity.

$\mathrm{Ca}^{2+}$ transients had a small amplitude $(\Delta G / R$ peak amplitude: $0.06 \pm 0.004$; Fig. $2 A, B 1)$. However, increasing the stimulus intensity by $10-100 \%$ was associated with a generation of supralinear $\mathrm{Ca}^{2+}$ signals that were almost five times higher than subthreshold postsynaptic $\mathrm{Ca}^{2+}$ transients $(\Delta G / R$ peak amplitude: $0.26 \pm 0.02, n=28$; Fig. $2 A, B 2)$. Generation of supralinear $\mathrm{Ca}^{2+}$ signals was always associated with somatic spiking (2-4 APs; Fig. 2A, C,D). However, both the slope of somatic voltage responses (Fig. 2E) and the number of somatic APs (Fig. 2F) increased linearly, indicative of the gradual recruitment of an increasing number of synapses. Dendritic $\mathrm{Ca}^{2+}$ nonlinearities were induced in both BCs and BISs as well as in some other unidentified CA1 FS interneurons, which were not included in this study. Importantly, BCs and BISs exhibited a similar degree of summation of postsynaptic $\mathrm{Ca}^{2+}$ signals, pointing to a common mechanism for their initiation in different subtypes of FS interneurons.

\section{Mechanisms of $\mathrm{Ca}^{2+}$ nonlinearities}

To study the mechanisms of $\mathrm{Ca}^{2+}$ nonlinearities, we next examined their sensitivity to the NMDAR and AMPAR blockers. Con- sistent with a minor role of NMDARs at these synapses (Fig. 1), blocking NMDARs had only a small effect on the amplitude of $\mathrm{Ca}^{2+}$ nonlinearities (decrease to $77.3 \pm 7.2 \%$ of control, $n=19$, $p<0.05$; $t$ test; Fig. $3 A, B)$. The presence of the NMDAR antagonist slightly decreased the degree of summation of $\mathrm{Ca}^{2+}$ transients but the summation remained supralinear $(p<0.05 ; n=$ 16, ANOVA; Fig. $3 C, D$ ), indicating that NMDARs contribute to supralinear $\mathrm{Ca}^{2+}$ signals but are not essential for their generation. In contrast, blocking CP-AMPARs resulted in a strong inhibition of these events (NASPM: decrease to $23.1 \pm 9.6 \%$ of control, $n=10, p<0.001$, $t$ test; PhTx: decrease to $19.5 \pm 5.0 \%$ of control, $n=4, p<0.001$, $t$ test; Fig. $3 A, B)$. The effect of PhTx was not associated with blocking nicotinic acetylcholine receptors (nAChRs) as the nAChR antagonist $d \mathrm{TC}$ had no effect on supralinear $\mathrm{Ca}^{2+}$ transients $(p=0.32, t$ test, $n=3$; Fig. $3 B$ ). Furthermore, summation of $\mathrm{Ca}^{2+}$ transients became linear in the presence of the CP-AMPAR antagonist NASPM $(n=7$; Fig. $3 C, D)$. The residual NASPM-resistant component of supralinear $\mathrm{Ca}^{2+}$ signals was blocked by the broad-spectrum AMPA/kainate receptor antagonist NBQX (Fig. 3A2,B), indicative of a partial blockade of CP-AMPARs by NASPM (Le Roux et al., 2013) or of 

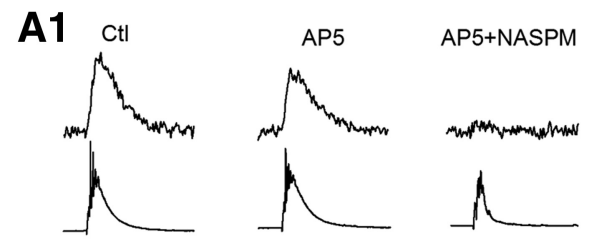

A2

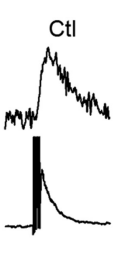

NASPM

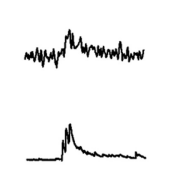

B

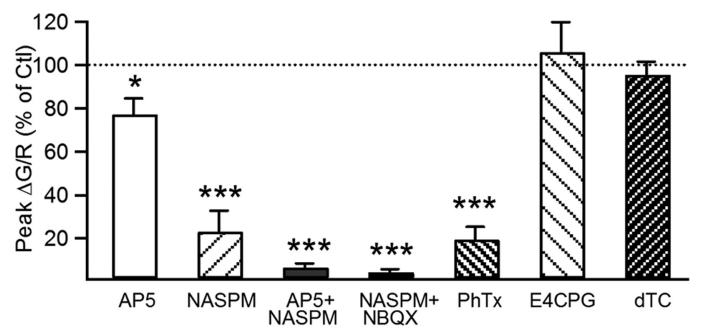

C
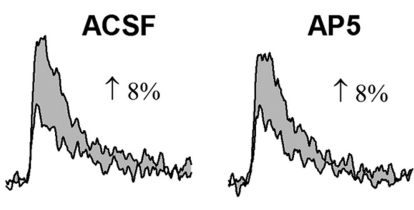

NASPM

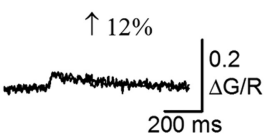

D

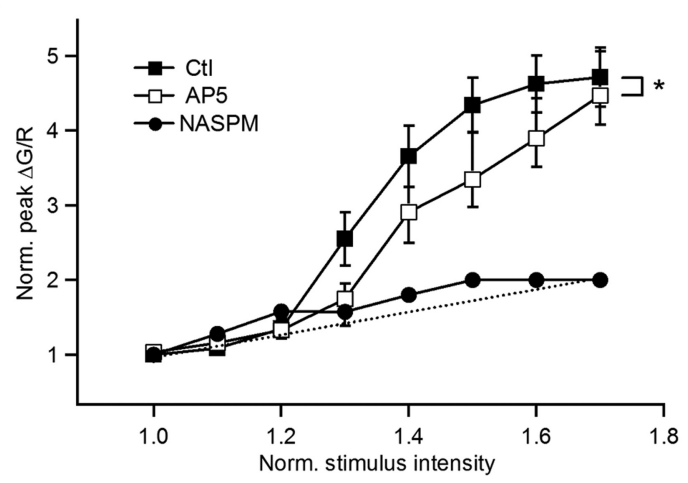

Figure 3. Supralinear $\mathrm{Ca}^{2+}$ signals are mediated by $\mathrm{Ca}^{2+}$-permeable AMPA receptors, with a minor contribution from NMDARs. $A$, Representative examples of supralinear $\mathrm{Ca}^{2+}$ signals and corresponding somatic voltage responses (with APs truncated) evoked in control (Ctl; left) and in the presence of glutamatergic receptor blockers DL-AP5 ( $\boldsymbol{A} 1$, middle), NASPM ( $\boldsymbol{A}$ 1, right; $\boldsymbol{A 2}$, middle), and NBQX (A2, right). B, Summary data showing changes in the amplitude of supralinear $\mathrm{Ca}^{2+}$ signals in the presence of pharmacological blockers, as a percentage of control. $\boldsymbol{C}$, Representative examples of supralinear $\mathrm{Ca}^{2+}$ signals evoked in three different cells by ramping up the stimulation in control (left), in the presence of DL-AP5 (middle), and in the presence of NASPM (right). D, Summary plot showing the effect of DL-AP5 and NASPM on the summation of postsynaptic $\mathrm{Ca}^{2+}$ signals.

an additional recruitment of kainate receptors (Cossart et al., 1998). In any case, this residual component's amplitude was small and was insufficient for the induction of supralinear $\mathrm{Ca}^{2+}$ signals (Fig. $3 C, D$ ). These results demonstrate that CP-AMPARs, not NMDARs, play a major role in synaptically evoked supralinear $\mathrm{Ca}^{2+}$ signals in distal dendrites of FS interneurons.

As CP-AMPARs could contribute to supralinear $\mathrm{Ca}^{2+}$ transients by providing postsynaptic depolarization necessary for the activation of VGCCs, we next examined the role of VGCCs in the generation of $\mathrm{Ca}^{2+}$ nonlinearities. Blocking L- or T-type VGCCs had no effect on the summation of postsynaptic $\mathrm{Ca}^{2+}$ transients. The L-type VGCC antagonist nifedipine $(10 \mu \mathrm{m})$ reduced the amplitude of supralinear $\mathrm{Ca}^{2+}$ events $(78.1 \pm 5.1 \%$ of control, $p=0.053, n=5, t$ test) but did not affect the summation of postsynaptic $\mathrm{Ca}^{2+}$ transients (Fig. $4 A, B, F$ ). No effects on the amplitude or summation of postsynaptic $\mathrm{Ca}^{2+}$ transients were found with T-type VGCC inhibitor NNC 55-0396 (10 $\mu \mathrm{M}$; Fig. $4 C, D, F)$ or nickel $\left(\mathrm{Ni}^{2+} ; 50 \mu \mathrm{M}\right.$; data not shown), consistent with a postnatal downregulation of the T-type VGCC Cav3.1 in FS interneurons (Iftinca and Zamponi, 2009; Okaty et al., 2009). The use of the R-type VGCC antagonist SNX-482 (30 nM) resulted in a strong inhibition of somatic responses $(n=3$; data not shown), preventing us from studying the specific role of these channels in $\mathrm{Ca}^{2+}$ nonlinearities. Furthermore, postsynaptic $\mathrm{Ca}^{2+}$ transients summated nonlinearly in the presence of the sodium channel blocker QX-314 ( $n=3$; Fig. $4 E)$. These results indicate that CPAMPARs do not act via activation of sodium and L- or T-type calcium channels but, instead, may provide a direct $\mathrm{Ca}^{2+}$ influx involved in the generation of $\mathrm{Ca}^{2+}$ nonlinearities.

To test this hypothesis, we next examined the calcium dependency of supralinear $\mathrm{Ca}^{2+}$ events (Fig. 5). We found that the threshold for initiation of supralinear $\mathrm{Ca}^{2+}$ signals was lower in cells that exhibited a higher subthreshold postsynap- tic $\mathrm{Ca}^{2+}$ influx (Pearson correlation: $r=-0.73, p=0.0113$; Fig. 5A-C, red traces and symbols), pointing to the $\mathrm{Ca}^{2+}$ sensitivity of supralinear $\mathrm{Ca}^{2+}$ signals. The latter was not a result of an additional contribution of NMDARs at some synapses, as higher NMDAR content had no effect on the amplitude of subthreshold $\mathrm{Ca}^{2+}$ influx (Pearson correlation: $r=0.29, p=$ $0.44)$ or on the threshold for initiation of supralinear $\mathrm{Ca}^{2+}$ signals (Pearson correlation: $r=-0.38, p=0.32$; Fig. $5 D, E$ ). These data point to a specific role of CP-AMPAR-mediated $\mathrm{Ca}^{2+}$ influx in generation of $\mathrm{Ca}^{2+}$ nonlinearities. As supralinear $\mathrm{Ca}^{2+}$ signals were associated with a substantial somatic depolarization (Fig. 2), which could hamper CP-AMPARmediated $\mathrm{Ca}^{2+}$ influx in the presence of intracellular polyamine, we wondered whether excluding spermine from the intracellular solution had any effect on the generation of $\mathrm{Ca}^{2+}$ nonlinearities. Both the amplitude of supralinear $\mathrm{Ca}^{2+}$ events and the threshold for their initiation were not affected by omitting spermine from the intracellular solution $(\Delta G / R$ peak amplitude with spermine: $0.27 \pm 0.01, n=19 ; \Delta G / R$ peak amplitude without spermine: $0.26 \pm 0.03, n=22$; threshold with spermine: $45.6 \pm 6.7 \mu \mathrm{A}$; threshold without spermine: $45.0 \pm 10.9 \mu \mathrm{A}, p>0.05$, Mann-Whitney test). These findings indicate that intracellular polyamines have no effect on dendritic $\mathrm{Ca}^{2+}$ nonlinearities, likely due to the insufficient membrane depolarization achieved in distal dendritic branches during initiation of supralinear $\mathrm{Ca}^{2+}$ events. In contrast, increasing the CP-AMPAR $\mathrm{Ca}^{2+}$ influx by membrane hyperpolarization during synaptic stimulation lowered the threshold for initiation of $\mathrm{Ca}^{2+}$ nonlinearities (stimulation threshold at $-70 \mathrm{mV}: 69.0 \pm 4.1 \mu \mathrm{A}$; stimulation threshold at $-90 \mathrm{mV}: 43.3 \pm 2.4 \mu \mathrm{A}, n=3$ ). Collectively, these results indicate that synaptically generated supralinear $\mathrm{Ca}^{2+}$ events rely on $\mathrm{Ca}^{2+}$ influx via CP-AMPARs. 
A1

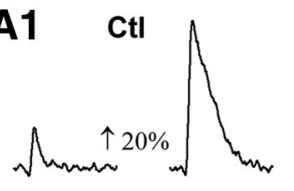

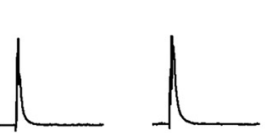

A2
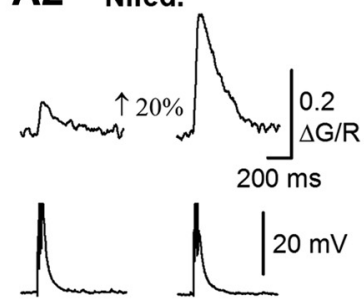

B

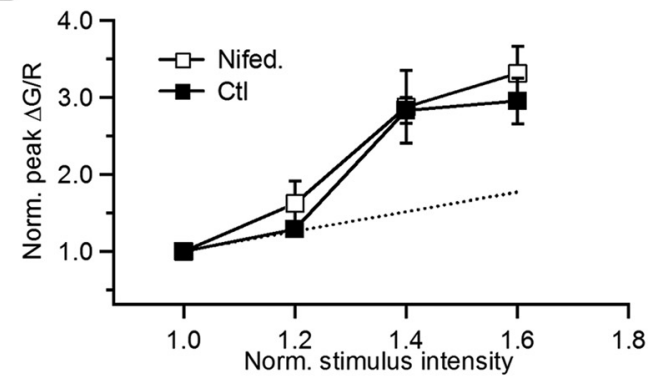

$\mathbf{E}$

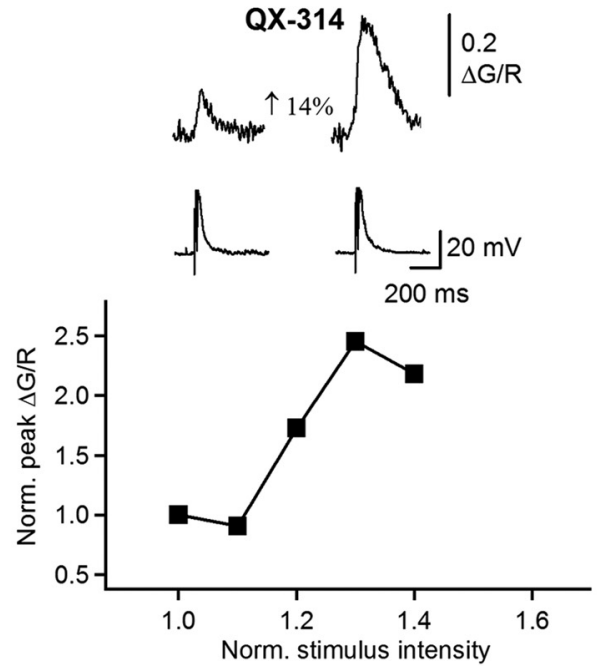

C1 Ctl
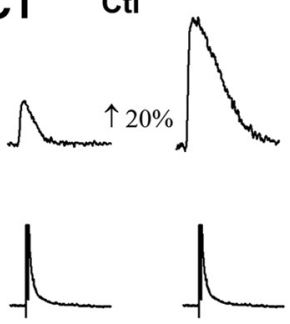

C2 NNC 55-0396

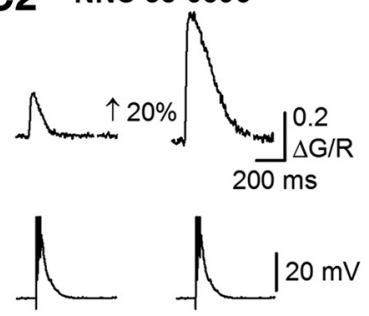

D

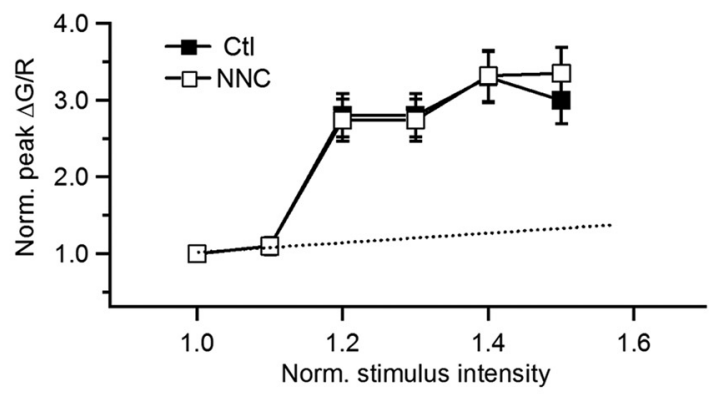

F

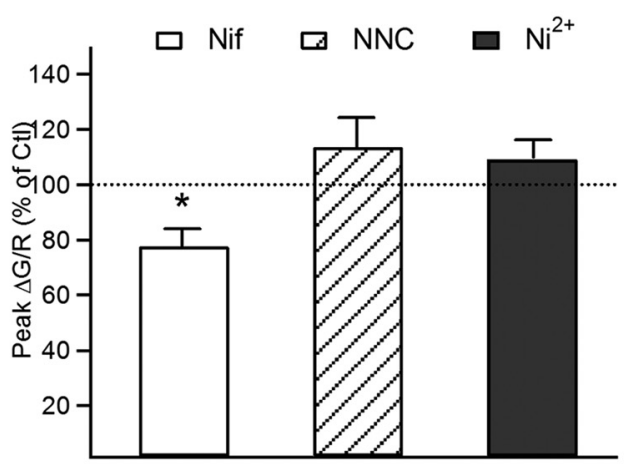

Figure 4. $\quad \mathrm{Ca}^{2+}$ nonlinearities in distal dendrites do not involve voltage-gated $\mathrm{Ca}^{2+}$ and $\mathrm{Na}^{+}$channels. $A$, Representative examples of supralinear $\mathrm{Ca}^{2+}$ events (top) and corresponding voltage responses (bottom; with APs truncated) elicited with a 20\% raise in stimulation intensity, in control (Ctl; $\boldsymbol{A}$ ) and in the presence of L-type VGCC antagonist nifedipine (Nifed; $\boldsymbol{A 2}$ ). $\boldsymbol{B}$, Summary plot showing the effect of nifedipine on the initiation of $\mathrm{Ca}^{2+}$ nonlinearities (dotted line indicates the linear fit between the first two values). $C$, Representative examples of nonlinear $\mathrm{Ca}^{2+}$ events (top) and corresponding voltage responses (bottom; with APs truncated) elicited with a 20\% raise in stimulation intensity, in control (C1) and in the presence of T-type VGCC antagonist NNC 55 - 0396 (NNC; C2).D, Summary plot showing the effect of NNC 55- 0396 on the initiation of $\mathrm{Ca}^{2+}$ nonlinearities (dotted line indicates the linear fit between the first two values). $\boldsymbol{E}$, Nonlinear $\mathrm{Ca}^{2+}$ events (top) and corresponding voltage responses (bottom; with APs truncated) elicited with a $14 \%$ raise in stimulation intensity, in the presence of $\mathrm{Na}^{+}$channel blocker QX-314. Summary plot is shown

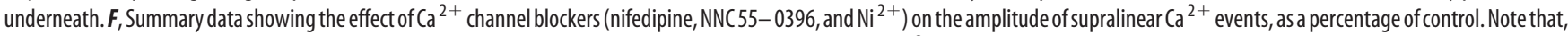
in all cases, a $14-20 \%$ increase in the stimulation intensity was associated with the generation of supralinear $\mathrm{Ca}^{2+}$ responses, indicating that $\mathrm{VGCCs}$ and sodium channels are not involved in the generation of dendritic $\mathrm{Ca}^{2+}$ nonlinearities.

Previous evidence indicates that $\mathrm{Ca}^{2+}$-induced $\mathrm{Ca}^{2+}$ release (CICR) from intracellular stores can amplify the postsynaptic $\mathrm{Ca}^{2+}$ signal (Wang et al., 2000; Nakamura et al., 2002; Watanabe et al., 2006). To study whether this mechanism can operate in distal dendrites of FS interneurons, we examined the sensitivity of $\mathrm{Ca}^{2+}$ nonlinearities to pharmacological manipulations of $\mathrm{Ca}^{2+}$ release (Fig. 6). Our data showed that the summation of postsynaptic $\mathrm{Ca}^{2+}$ transients became linear in the presence of CPA, a specific blocker of smooth endoplasmic reticulum $\mathrm{Ca}^{2+} /$ ATPases (SERCA; Fig. $6 A, E$ ), or ryanodine (Fig. $6 B, E)$. Moreover, priming the intracellular stores by local puff application of caffeine ( $1 \mathrm{~mm}, 50 \mathrm{~ms})$, the ryanodine receptor agonist, decreased the threshold for the initiation of supralin- ear $\mathrm{Ca}^{2+}$ transients $(p<0.05, n=4, t$ test; Fig. $6 C)$ without affecting their amplitude ( $p>0.05, n=4, t$ test; Fig. $6 E)$. These data point to a major role of CICR in the generation of $\mathrm{Ca}^{2+}$ nonlinearities. As both NMDARs and L-type VGCCs made a significant contribution to supralinear $\mathrm{Ca}^{2+}$ signals (Figs. $3 B, 4 F$ ) and together could provide $\mathrm{Ca}^{2+}$ influx necessary to induce $\mathrm{Ca}^{2+}$ release, we examined next whether blocking these two $\mathrm{Ca}^{2+}$ sources simultaneously may have a significant impact on the generation of $\mathrm{Ca}^{2+}$ nonlinearities. Our data showed that, compared with control recordings (Fig. $2 B)$, the degree of summation of $\mathrm{Ca}^{2+}$ transients was reduced but the summation remained supralinear $(n=4, p<0.05$, ANOVA; Fig. 6D), suggesting that CICR initiated by the spe- 

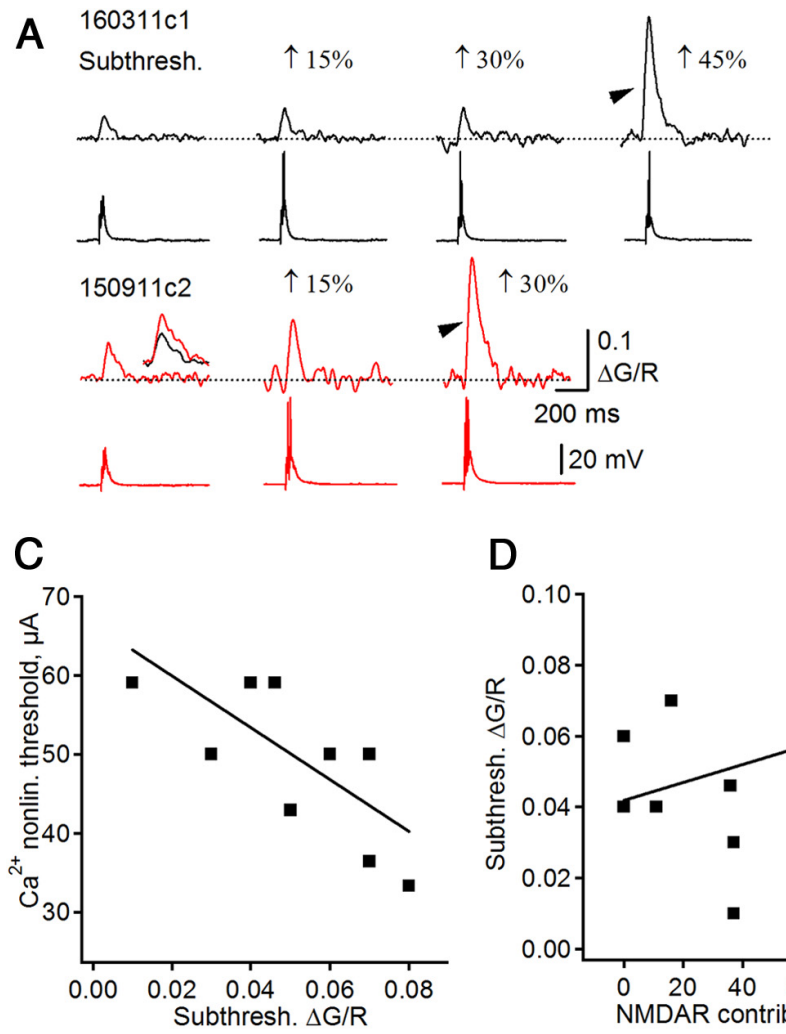

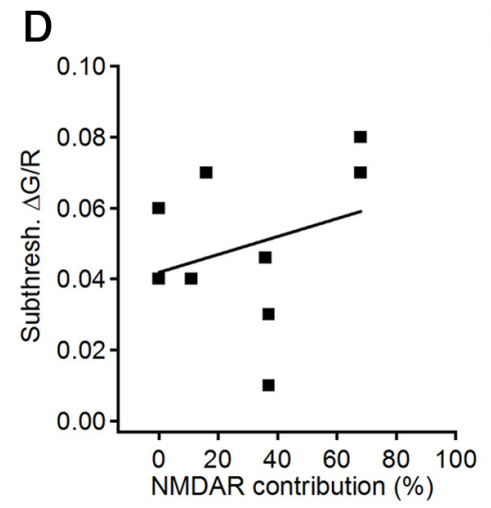

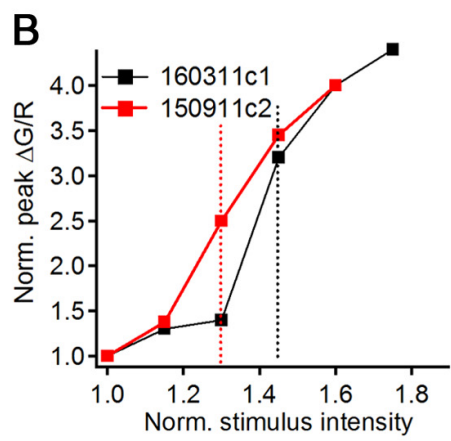

E

Figure 5. Calcium dependence of $\mathrm{Ca}^{2+}$ nonlinearities. $A$, Representative examples of postsynaptic $\mathrm{Ca}^{2+}$ transients (black arrows: $\mathrm{Ca}^{2+}$ nonlinearities) and corresponding voltage responses evoked by synaptic stimulation of different intensities [from subthreshold stimulation (for somatic AP generation) to $45 \%$ increase]. $\boldsymbol{B}$, Summary plot of $\mathrm{Ca}^{2+}$ transient peak amplitudes versus stimulus intensities (dotted lines: $\mathrm{Ca}^{2+}$ nonlinearity threshold). Note that a cell with subthreshold $\mathrm{Ca}^{2+}$ transients of higher amplitude (shown in red) had a lower threshold for the initiation of supralinear $\mathrm{Ca}^{2+}$ events. C, Summary data for a population of cells showing a significant negative correlation between the stimulus intensity required to evoke a supralinear $\mathrm{Ca}^{2+}$ event and the amplitude of subthreshold $\mathrm{Ca}^{2+}$ transients. D, E, Summary plots showing the absence of correlation between the contribution of the NMDAR to postsynaptic $\mathrm{Ca}^{2+}$ response and the amplitude of subthreshold $\mathrm{Ca}^{2+}$ transients $(\boldsymbol{D})$ or the threshold to induce a supralinear $\mathrm{Ca}^{2+}$ event $(\boldsymbol{E})$. NMDAR contribution was determined as the DL-AP-5-sensitive component. The threshold to induce a supralinear $\mathrm{Ca}^{2+}$ event was determined as the minimal intensity of stimulation $(\mu \mathrm{A})$ necessary to evoke the supralinear $\mathrm{Ca}^{2+}$ event.
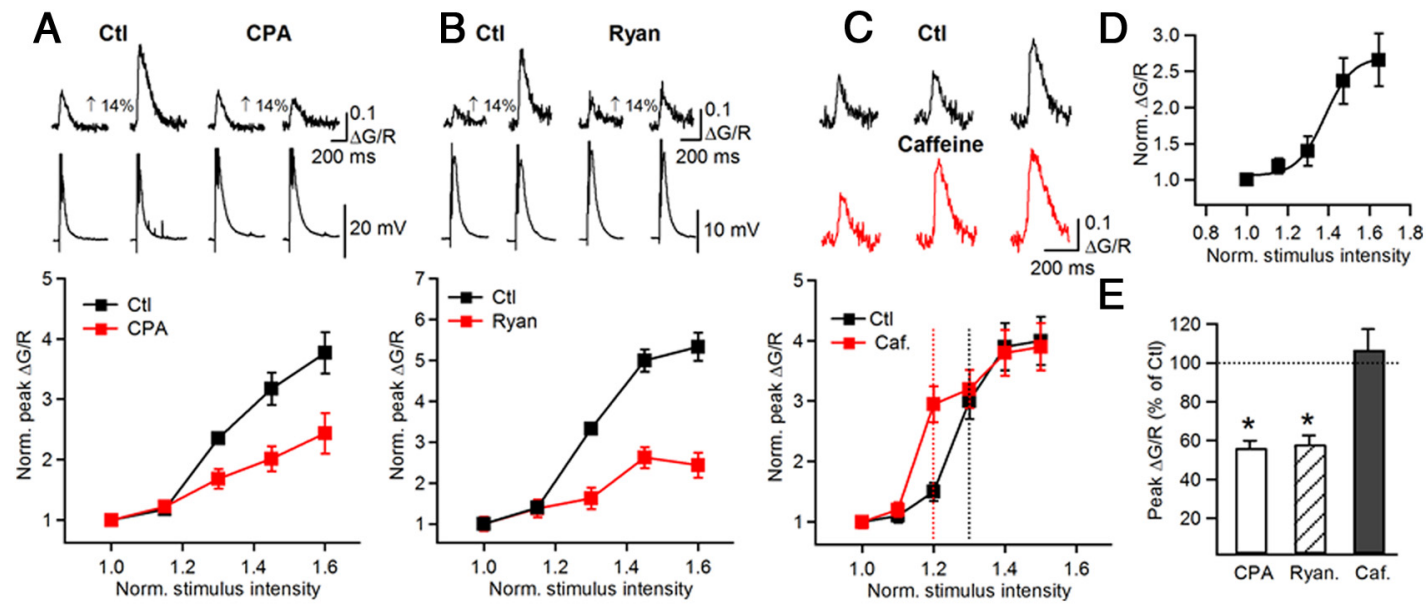

Figure 6. $\mathrm{Ca}^{2+}$ nonlinearities are produced by $\mathrm{Ca}^{2+}$-induced $\mathrm{Ca}^{2+}$ release. $A-C$, Representative examples of supralinear $\mathrm{Ca}^{2+}$ responses with corresponding voltage responses (with APs truncated; top) and summary plots (bottom) illustrating the summation of postsynaptic $\mathrm{Ca}^{2+}$ transients under different conditions ( $\boldsymbol{A},(\mathrm{CP} ; \boldsymbol{B}, \boldsymbol{B}$, Ryanodine, Ryan; $\boldsymbol{C}$, caffeine, Caf). Vertical dotted lines on the summary plot at $C$ indicate the threshold for initiation of supralinear $\mathrm{Ca}^{2+}$ signals. D, Summary plot illustrating the summation of postsynaptic $\mathrm{Ca}^{2+}$ transients in the presence of the NMDAR blocker DL-AP5 and the L-type VGCC inhibitor nifedipine. E, Summary data showing the effects of CPA, ryanodine, and caffeine on the peak amplitude of supralinear $\mathrm{Ca}^{2+}$ signals, as a percentage of control (Ctl). Note that $\mathrm{Ca}^{2+}$ responses summated linearly in the presence of $\mathrm{Ca}^{2+}$ release blockers $\mathrm{CPA}$ and ryanodine.

cific activation of CP-AMPARs is sufficient for the generation of $\mathrm{Ca}^{2+}$ nonlinearities. We did not observe the participation of group I/II mGluRs in supralinear $\mathrm{Ca}^{2+}$ signals induced by single bursts of synaptic stimulation because these events were completely blocked by a combination of DL-AP5, NASPM, and NBQX $(n=3$; Fig. $3 A 2, B)$ and were not sensitive to the group I/II mGluR antagonist E4CPG $(n=5, p>0.05, t$ test; Fig. $3 B)$. Thus, intracellular $\mathrm{Ca}^{2+}$ release initiated by $\mathrm{Ca}^{2+}$ influx 


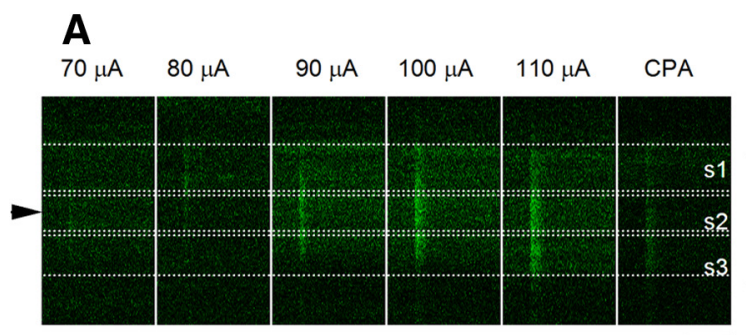

B

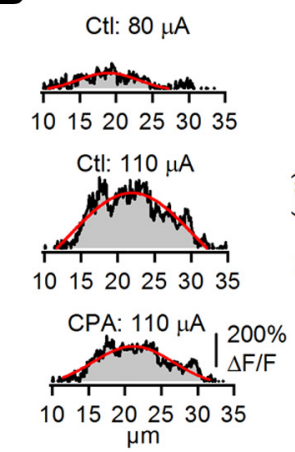

D

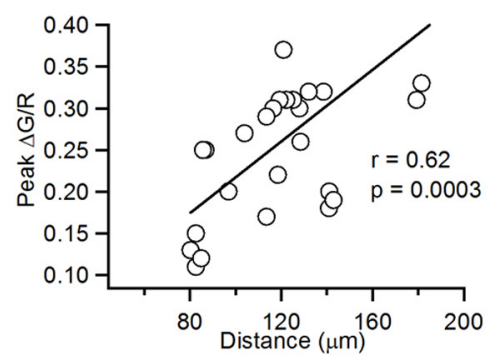

$\mathbf{E}$
$200 \mathrm{~ms}$ C

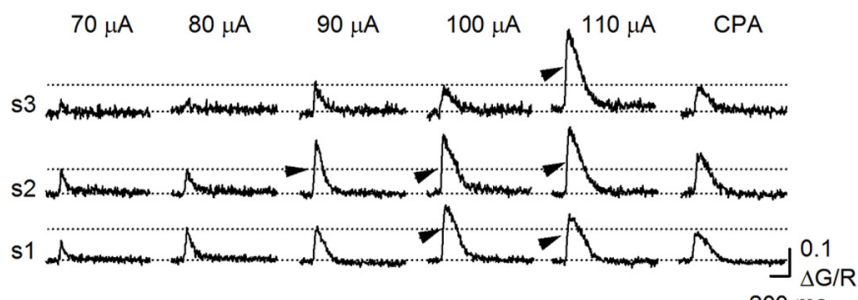

$200 \mathrm{~ms}$
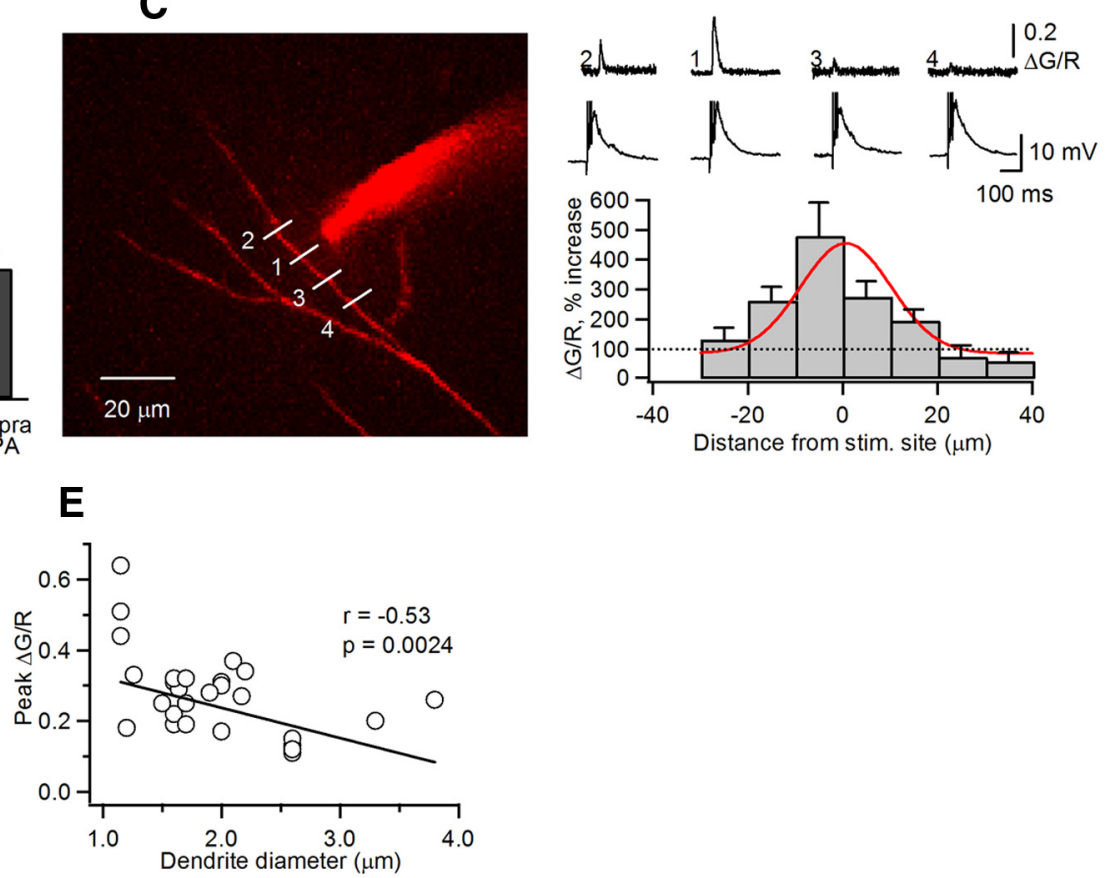

Figure 7. Spatial profile of $\mathrm{Ca}^{2+}$ nonlinearities. $A$, Simultaneous line scan imaging of three neighboring dendritic segments during different intensities of stimulation in control ( $(\mathrm{tl} ; 70-110 \mu \mathrm{A})$ and in the presence of $\mathrm{CPA}\left(110 \mu \mathrm{A}\right.$; left) and corresponding $\mathrm{Ca}^{2+}$ responses detected in these segments under different conditions (right). The arrowhead to the left of the line scan images indicates the location of the stimulation pipette. The arrowheads to the right point to dendritic nonlinearities. $\boldsymbol{B}$, Spatial profile graphs illustrating the spatial extent of subthreshold (Sub; top) and supralinear (Supra; middle) $\mathrm{Ca}^{2+}$ responses, as well as supralinear responses in the presence of CPA. Data are summarized alongside, with the SD from the peak serving as an approximation of spatial extent. C, Two-photon image of distal branches showing the location of the line scan measurements used to assess the spatial extent of $\mathrm{Ca}^{2+}$ nonlinearities (left), along with their corresponding responses (right, top), and summary plot of the $\mathrm{Ca}^{2+}$ nonlinearity peak amplitude versus distance from the stimulation site (right, bottom). Red curve indicates a Gaussian fit. D, E, Summary plots showing the relationship between the amplitude of supralinear $\mathrm{Ca}^{2+}$ signals and distance from the soma $(\boldsymbol{D})$ or dendrite diameter $(\boldsymbol{E})$.

through CP-AMPARs is a primary mechanism of supralinear $\mathrm{Ca}^{2+}$ signals generated in FS interneurons.

\section{Spatial profile of dendritic $\mathrm{Ca}^{2+}$ nonlinearities}

The spatial extent of $\mathrm{Ca}^{2+}$ release events can vary from spatially restricted $\mathrm{Ca}^{2+}$ "sparks" to regenerative $\mathrm{Ca}^{2+}$ waves (Berridge, 1998; Callamaras et al., 1998; Watanabe et al., 2006; Manita and Ross, 2009; Miyazaki and Ross, 2013). To study the spatial profile of $\mathrm{Ca}^{2+}$ nonlinearities in dendritic branches of FS interneurons, we first performed fast line scan imaging along dendritic segments of 10-15 $\mu \mathrm{m}$-length. Upon initiation, supralinear $\mathrm{Ca}^{2+}$ signals were restricted within small dendritic microdomains (6.0 $\pm 0.9 \mu \mathrm{m}, n=6$; Fig. $7 A)$ and remained localized within individual dendritic branches when a supralinear $\mathrm{Ca}^{2+}$ event was generated $(11.2 \pm 2.3 \mu \mathrm{m}, n=6$; Fig. $7 A, B)$. The SERCA pump inhibitor CPA removed the supralinear component of $\mathrm{Ca}^{2+}$ events but did not affect significantly the spatial extent of $\mathrm{Ca}^{2+}$ events ( $7.8 \pm 0.8 \mu \mathrm{m}, n=6, p>0.05, t$ test; Fig. $7 A, B)$, consistent with a major role of $\mathrm{Ca}^{2+}$ release in local $\mathrm{Ca}^{2+}$ nonlinearities. To further examine the possible propagation of supralinear $\mathrm{Ca}^{2+}$ events, we performed line scan imaging across dendritic segments at different locations from the stimulation site (Fig. 7C, left). The focal plane was adjusted according to the $z$-position of the dendrite. The summation of postsynaptic $\mathrm{Ca}^{2+}$ transients was examined in each location by raising the stimulus intensity gradually up to $200 \%$ from the initial stimulus strength necessary to evoke the postsynaptic $\mathrm{Ca}^{2+}$ signal. Under these recording conditions, supralinear $\mathrm{Ca}^{2+}$ signals were also seen within individual dendritic branches $(13.5 \pm 2.1 \mu \mathrm{m}$; Fig. $7 C$, right). In addition, we found that supralinear $\mathrm{Ca}^{2+}$ events increased their amplitude with distance from the soma (Pearson correlation: $r=$ $0.62, p=0.0003$; Fig. $7 D$ ) and were significantly higher in secondary and tertiary dendritic branches because of the smaller dendritic diameter (Pearson correlation: $r=-0.53, p=0.0024$; Fig. 7E). This shows that in FS interneurons, supralinear $\mathrm{Ca}^{2+}$ events occur primarily within distal secondary and tertiary dendritic branches and remain localized.

\section{Functional role of dendritic $\mathrm{Ca}^{2+}$ nonlinearities}

At excitatory synapses of pyramidal neurons, supralinear $\mathrm{Ca}^{2+}$ events have been consistently associated with induction of LTP (Magee and Johnston, 1997; Koester and Sakmann, 1998; Gold- 


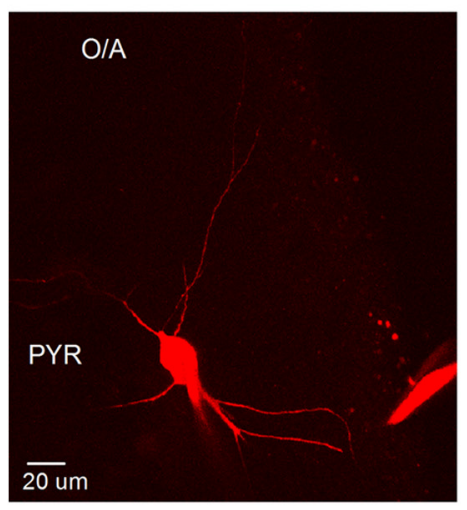

A

B1
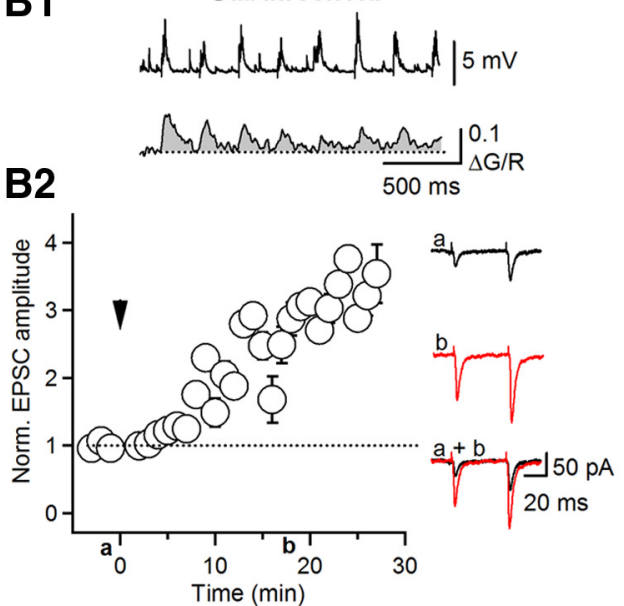

D1 Suprathreshold/ CPA
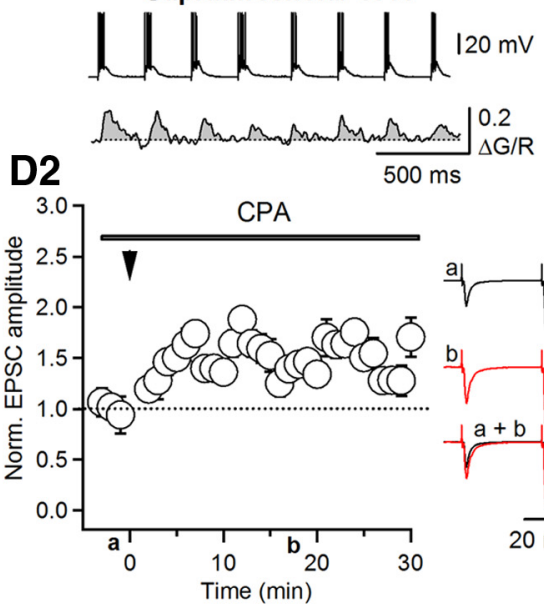

E1
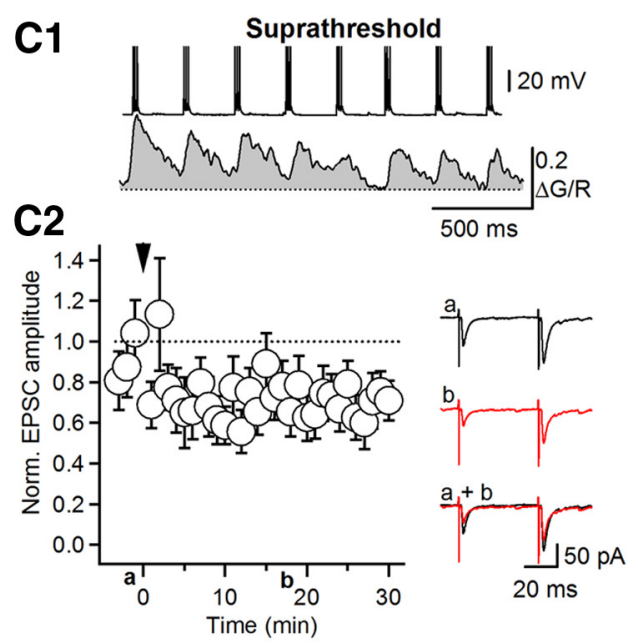

Figure 8. $\quad \mathrm{Ca}^{2+}$ nonlinearities control the direction of plasticity. $\boldsymbol{A}$, Two-photon image showing the location of the stimulation electrode used to induce synaptic plasticity. $\boldsymbol{B}-\boldsymbol{E}$, Representative examples of somatic responses and dendritic $\mathrm{Ca}^{2+}$ fluctuations evoked by different types of TBS under different conditions (B1-E1) along with summary time plots of normalized EPSC amplitude (B2-E2, left) and with representative examples of EPSCs recorded before and after TBS (B2-E2, right). The black arrowhead above plots indicates the onset of TBS. In different experiments, TBS was applied at a subthreshold (for somatic AP generation) stimulation level (B1), a suprathreshold stimulation level producing $\mathrm{Ca}^{2+}$ nonlinearity (C1), a suprathreshold stimulation level in the presence of CPA (D1), or a suprathreshold stimulation level in the presence of the group I mGluR antagonist E4CPG (E1). $\boldsymbol{F}$, Summary graph showing the changes in Ca ${ }^{2+}$ fluctuations (area under the curve) during TBS for the four conditions. Ctl, control. 0/A, Oriens/alveus.

ing et al., 2002; Dan and Poo, 2004). To test whether $\mathrm{Ca}^{2+}$ nonlinearities can regulate synaptic efficacy at excitatory synapses of FS interneurons, we examined how their generation at theta frequency, a natural pattern of hippocampal activity, affects the efficacy of transmission at distal excitatory synapses (Fig. 8). Interneurons were voltage clamped at $-70 \mathrm{mV}$ and EPSCs were evoked by local bipolar stimulation of distal inputs in the stratum oriens/alveus (100-250 $\mu \mathrm{m}$ from the soma; Fig. $8 A$ ). After a baseline recording, TBS (three trains at $4 \mathrm{~Hz}$ for $2 \mathrm{~s}$ with $30 \mathrm{~s}$ intervals) was applied to interneurons held in current-clamp mode, after which the voltage-clamp recordings of EPSCs were resumed. Consistent with previous findings (Lamsa et al., 2007; Oren et al., 2009; Nissen et al., 2010; Griguoli et al., 2013), low-intensity (subthreshold for somatic AP generation) TBS at rest $\left(V_{\mathrm{m}}=-70\right.$ $\mathrm{mV}$ ) applied within $8 \mathrm{~min}$ of whole-cell recording produced LTP (EPSC amplitude, $264.3 \pm 26.3 \%$ of control; Fig. $8 B 2 ; n=7, p<$ $0.05, t$ test). Postsynaptic $\mathrm{Ca}^{2+}$ transients evoked by the same stimulation paradigm in a separate series of experiments had a small amplitude $(\Delta G / R$ peak amplitude: $0.07 \pm 0.01 ;$ Fig. $8 B 1, F)$, consistent with the absence of supralinear $\mathrm{Ca}^{2+}$ events under basal conditions. Surprisingly, increasing the stimulation inten- sity during TBS (100\% from the baseline level) to trigger dendritic $\mathrm{Ca}^{2+}$ nonlinearities (Fig. $8 C 1, F$ ) induced LTD at these synapses (EPSC amplitude: $70.2 \pm 13.2 \%$ of control; Fig. 8C2; $n=7, p<0.05, t$ test). $\mathrm{Ca}^{2+}$ signals evoked by such suprathreshold TBS in a separate series of experiments had a large amplitude ( $\Delta G / R$ peak amplitude: $0.28 \pm 0.02, n=5$ ), consistent with the induction of supralinear $\mathrm{Ca}^{2+}$ events. Blocking internal $\mathrm{Ca}^{2+}$ release by CPA during suprathreshold TBS resulted in a significant decrease of supralinear $\mathrm{Ca}^{2+}$ events and in a switch in plasticity direction from LTD back to LTP (EPSC amplitude: $141.4 \pm$ $4.6 \%$ of control; Fig. $8 D, F ; n=5, p<0.05$, $t$ test). To test whether the CPA application affects presynaptic $\mathrm{Ca}^{2+}$ release (Simkus and Stricker, 2002; Martín and Buño, 2003), which could contribute to plastic changes, we analyzed the properties of sEPSCs and evoked EPSCs (eEPSC) as well as the area under curve of TBS-evoked somatic responses in control and in the presence of CPA. Our data showed that the amplitude, frequency, and kinetics of sEPSCs were not affected by CPA application (amplitude control: $18.8 \pm 0.4 \mathrm{pA}$; amplitude CPA: $17.7 \pm 0.3 \mathrm{pA}$; frequency control: $5.1 \pm 0.8 \mathrm{~Hz}$; frequency CPA: $6.8 \pm 1.7 \mathrm{~Hz}$; rise control: $0.36 \pm 0.01 \mathrm{~ms}$; rise CPA: $0.35 \pm 0.03 \mathrm{~ms}$; decay control: $2.33 \pm$ 
0.09 ms; decay CPA: $2.25 \pm 0.06 \mathrm{~ms} ; n=4, p<0.05$, MannWhitney test). Moreover, CPA had no effect on the paired-pulse ratio (PPR) of eEPSCs (PPR control: $1.85 \pm 0.12, n=7$; PPR CPA: $1.86 \pm 0.19, n=5 ; p<0.05$, Mann-Whitney test). Furthermore, somatic voltage responses evoked by suprathreshold TBS were also not affected by CPA application (area under curve control: $1070 \pm 236 \mathrm{mV} \times \mathrm{ms}$; area under curve CPA: $1315 \pm$ $171 \mathrm{mV} \times \mathrm{ms}, n=5, p<0.05$, Mann-Whitney test). Together, these data indicate that, similar to other types of excitatory synapses (Carter et al., 2002), presynaptic $\mathrm{Ca}^{2+}$ stores do not contribute to transmitter release at CA1 synapses to FS interneurons.

As suprathreshold TBS could activate postsynaptic group I mGluRs, which also contribute to internal $\mathrm{Ca}^{2+}$ release, we examined the sensitivity of supralinear $\mathrm{Ca}^{2+}$ signals to the group I/II mGluR antagonist E4CPG (Fig. 8E1,F). Whereas E4CGP had no effect on the peak amplitude of supralinear $\mathrm{Ca}^{2+}$ events evoked by single bursts (Figs. 3B, 8E1; first burst in the train), it decreased significantly the area under the curve of the TBS-induced supralinear $\mathrm{Ca}^{2+}$ elevation (Fig. $8 F ; n=5$, $p<0.05, t$ test $)$, indicating that mGluR-mediated postsynaptic $\mathrm{Ca}^{2+}$ release contributes to this signal. Accordingly, blocking group I/II mGluRs during suprathreshold TBS resulted in STD (EPSC amplitude $62.4 \pm 13 \%$ of control; $n=4, p<0.05$, $t$ test) with a complete recovery of EPSC amplitude within 15 min after induction (Fig. 8E2). Hence, supralinear $\mathrm{Ca}^{2+}$ events resulting from the $\mathrm{Ca}^{2+}$-induced $\mathrm{Ca}^{2+}$ release following the activation of CP-AMPARs switch the direction of synaptic plasticity from LTP to STD. Furthermore, additional recruitment of mGluRs, which takes place during repetitive theta-like activity, converts STD to a longer lasting depression.

\section{Discussion}

Here, we investigated the mechanisms and functional significance of supralinear $\mathrm{Ca}^{2+}$ signals generated by synchronous activation of excitatory synapses in distal dendritic branches of hippocampal CA1 FS interneurons. Our major findings are that supralinear $\mathrm{Ca}^{2+}$ signals (1) require $\mathrm{Ca}^{2+}$ influx through CP-AMPARs with a subsequent $\mathrm{Ca}^{2+}$ release; (2) remain localized within individual dendritic branches; and (3) switch the direction of synaptic plasticity from LTP to STD or LTD, depending on the additional recruitment of group I/II mGluRs. We conclude that, by linking together different signaling cascades, intracellular $\mathrm{Ca}^{2+}$ release in dendrites of FS interneurons provides a reliable and dynamically regulated source of $\mathrm{Ca}^{2+}$ that may signal coincident activation of synaptic inputs and, thus, represents an important mechanism in the regulation of synaptic strength.

\section{Mechanisms of $\mathrm{Ca}^{2+}$ nonlinearities in FS interneurons}

Our results provide new insights into mechanisms of regenerative activity in distal dendrites of interneurons. Consistent with previous findings in neocortical FS cells and hippocampal CA1 PV-positive interneurons (Goldberg et al., 2003b; Le Roux et al., 2013), we found that the GluA2-lacking CPAMPARs provide a primary source of postsynaptic $\mathrm{Ca}^{2+}$ influx. CP-AMPARs were solely responsible for postsynaptic $\mathrm{Ca}^{2+}$ influx in $60 \%$ of synapses examined and mediated up to $80 \%$ of postsynaptic $\mathrm{Ca}^{2+}$ influx at rest. Accordingly, CPAMPARs played a major role in the induction of $\mathrm{Ca}^{2+}$ release resulting in the generation of dendritic supralinear $\mathrm{Ca}^{2+}$ events. NMDARs and L-type VGCCs made a minor contribution to $\mathrm{Ca}^{2+}$ nonlinearities but were not sufficient for their generation. Therefore, unlike the mechanisms described pre- viously (Schiller et al., 1997; Wang et al., 2000; Wei et al., 2001; Golding et al., 2002; Losonczy and Magee, 2006; Watanabe et al., 2006; Tsay et al., 2007), supralinear $\mathrm{Ca}^{2+}$ signals in FS interneurons do not rely on the activation of voltagedependent $\mathrm{Ca}^{2+}$ sources but require instead $\mathrm{Ca}^{2+}$ mechanisms activated mainly at rest. This mechanism may predominate in interneurons because of the highly variable distributions of voltagegated $\mathrm{Ca}^{2+}$ sources (e.g., NMDARs; Lei and McBain, 2002; Goldberg et al., 2003b; Nyíri et al., 2003; Le Roux et al., 2013). We did not find significant differences in the NMDAR contribution to synaptic responses between BCs and BISs, pointing to the lack of cell type-specific differences in NMDAR distribution within a population of FS interneurons. However, other excitatory projections that terminate within $\mathrm{CA} 1 \mathrm{O} / \mathrm{A}$ could be recruited in our experiments (Somogyi and Klausberger, 2005; Takács et al., 2012), pointing to the synapse-specific variations in NMDAR distribution in FS interneurons. This question will require further examination using selective optogenetic targeting of specific excitatory projections. Alternatively, limited functional availability of voltage-dependent $\mathrm{Ca}^{2+}$ mechanisms in distal dendritic branches resulting from the failure of AP backpropagation and insufficient membrane depolarization can explain the minor role of these mechanisms in supralinear $\mathrm{Ca}^{2+}$ signals (Goldberg et al., 2003a; Aponte et al., 2008; Hu et al., 2010). Under these conditions, AMPAR-store coupling allows the coincidence detection of activated synapses and the sitespecific regulation of synaptic strength depending on a number of synapses activated synchronously. Given the size of unitary excitatory responses at CA1 PC to FS interneuron synapses $(\sim 2$ $\mathrm{mV}$; Lacaille et al., 1987; Ali et al., 1998), the size of EPSPs evoked during supralinear $\mathrm{Ca}^{2+}$ signals $(\sim 10-15 \mathrm{mV})$ and the heavy innervation of FS cells (Gulyás et al., 1999), we estimate that at least $\sim 5-7$ synapses are required to generate a nonlinear $\mathrm{Ca}^{2+}$ event in dendritic compartment of $\sim 5 \mu \mathrm{m}$ (Fig. $7 A, B$ ). It should be pointed out that this measure is an approximation since the amplitude measurements during supralinear events were contaminated to some extent by sodium spikes riding on top of EPSPs. Further increase in the stimulation intensity was associated with recruitment of additional synapses and/or local spread of $\mathrm{Ca}^{2+}$ signals (Fig. 7C). However, no conclusion can be made regarding the actual number of synapses that may experience supralinear $\mathrm{Ca}^{2+}$ elevations under physiological conditions as the spatial extent of $\mathrm{Ca}^{2+}$ signals was likely overestimated due to the high mobility of synthetic $\mathrm{Ca}^{2+}$ indicators (Goldberg et al., 2003c).

Our data showed that ryanodine receptors (RyRs) mediate release of $\mathrm{Ca}^{2+}$ from internal stores in FS interneurons. RyR1 and, to a lesser degree, RyR2 are expressed in the CA1 hippocampal region (Hertle and Yeckel, 2007) and trigger fast and spatially localized $\mathrm{Ca}^{2+}$ "sparks" in dendrites of PCs (Manita and Ross, 2009; Miyazaki et al., 2012; Miyazaki and Ross, 2013), which appear similar to $\mathrm{Ca}^{2+}$ release events detected here. It should be pointed out that spontaneous $\mathrm{Ca}^{2+}$ release events have not been observed in our study, and their existence and degree of similarity with $\mathrm{Ca}^{2+}$ sparks described in cardiac myocytes (Cheng and Lederer, 2008) and hippocampal PCs (Manita and Ross, 2009; Miyazaki and Ross, 2013) need to be examined using a higher affinity $\mathrm{Ca}^{2+}$ indicator. Furthermore, we found that group I mGluR-mediated $\mathrm{Ca}^{2+}$ release makes an additional contribution to supralinear $\mathrm{Ca}^{2+}$ signals during repetitive suprathreshold TBS but not during single burst. The mGluR-mediated $\mathrm{Ca}^{2+}$ release likely involved the activation of mGluR5 (van Hooft et al., 2000) and 
RyRs (Topolnik et al., 2006, 2009), as PV-positive interneurons in this area do not express IP3 receptor 1 (Hertle and Yeckel, 2007) but exhibit RyR-mediated $\mathrm{Ca}^{2+}$ release following the activation of $\mathrm{G}_{\mathrm{q}}$-PLC signaling cascade (Lee et al., 2011). The absence of IP3 receptors, together with fast $\mathrm{Ca}^{2+}$ extrusion in PV-positive interneurons (Goldberg et al., 2003c), may explain why traveling $\mathrm{Ca}^{2+}$ waves were not observed in our study even following the group I mGluR activation during repetitive synaptic activity (Watanabe et al., 2006; Miyazaki and Ross, 2013).

\section{Functional role of dendritic $\mathrm{Ca}^{2+}$ nonlinearities}

Postsynaptic $\mathrm{Ca}^{2+}$ influx via CP-AMPARs has been associated with the induction of distinct forms of synaptic plasticity at excitatory synapses of hippocampal interneurons (Laezza et al., 1999; Lei and McBain, 2002; Lamsa et al., 2005, 2007; Oren et al., 2009; Sambandan et al., 2010). Activation of CPAMPARs together with group I mGluRs or $\alpha 7 \mathrm{nAChRs}$ at a relatively hyperpolarized level of the postsynaptic membrane potential can induce the so-called "anti-Hebbian" LTP (Lamsa et al., 2007; Oren et al., 2009; Nissen et al., 2010; Le Duigou and Kullmann, 2011; Szabo et al., 2012; Griguoli et al., 2013; Le Roux et al., 2013). In addition, short- and long-term synaptic depression was observed at GluA2 AMPAR-lacking synapses following the activation of group I mGluRs (Le Duigou et al., 2011) or tetanic stimulation of excitatory inputs (Laezza et al., 1999; Lei and McBain, 2002). Together, these findings indicate that GluA2 AMPAR-lacking synapses are capable of regulating the efficacy of transmission in a bidirectional manner. It should be pointed out, however, that, as different hippocampal regions, cell and synapse types, as well as induction paradigms have been studied by different groups, the mechanisms underlying multiple forms of plasticity at GluA2 AMPAR-lacking interneuron synapses are still not clear. As postsynaptic $\mathrm{Ca}^{2+}$ signal is a cornerstone in plasticity induction, we focused on examining how activity-dependent $\mathrm{Ca}^{2+}$ fluctuations may control the induction of plasticity at CP-AMPAR-dominated synapses of interneurons. Our data highlights the coexistence of multiple forms of plasticity in the same synapse by providing direct evidence for the activitydependent recruitment of additional $\mathrm{Ca}^{2+}$ mechanisms downstream of the CP-AMPAR $\mathrm{Ca}^{2+}$ influx. We demonstrate that, whereas small amplitude $\mathrm{Ca}^{2+}$ transients associated with subthreshold theta-like activity induce anti-Hebbian LTP, supralinear $\mathrm{Ca}^{2+}$ signals generated during suprathreshold thetaburst activity by the intracellular $\mathrm{Ca}^{2+}$ release induce LTD. The LTD induction required additional recruitment of group I/II mGluRs, as blocking these receptors converted LTD to STD. Thus, supralinear $\mathrm{Ca}^{2+}$ events generated by $\mathrm{Ca}^{2+}$ release following CP-AMPAR activation were responsible for STD. The expression site of different forms of synaptic plasticity observed here and the underlying signaling mechanisms remain to be determined. Previous findings showed that antiHebbian LTP is expressed presynaptically and, likely, involves the activation of a yet unknown retrograde messenger (Lamsa et al., 2007). Presynaptic expression of the group I mGluRdependent LTD was also reported. Importantly, postsynaptic group I mGluR activation and endocannabinoid release mediated LTD in CA1 FS interneurons (Péterfi et al., 2012). When compared with PCs, a higher stimulation frequency was required for this LTD induction due to the lower level of diacylglycerol lipase- $\alpha$ in interneurons. As application of the mGluR antagonist decreased significantly TBS-evoked post- synaptic $\mathrm{Ca}^{2+}$ signals in our experiments, we assume that postsynaptic group I mGluRs were involved in suprathreshold LTD. Thus, it will be plausible to examine the role of these receptors and of endocannabinoids in the STD and LTD observed here.

In conclusion, our data shed light on the $\mathrm{Ca}^{2+}$ mechanisms of plasticity induction at GluA2 AMPAR-lacking synapses and revealed a novel metaplastic mechanism by which synaptic weight can be transiently adjusted depending on the number of synapses activated synchronously. Moreover, as excitatory synapses in many types of neurons throughout the CNS may incorporate GluA2-lacking AMPA receptors earlier during development or following synaptic inactivity (Kumar et al., 2002; Thiagarajan et al., 2005), this mechanism may be important for the detection of coincident synaptic inputs in the absence of voltage-dependent $\mathrm{Ca}^{2+}$ sources and may provide additional ways for associative learning.

\section{Notes}

Supplemental material for this article is available at www.neuronimaging. ca. This material has not been peer reviewed.

\section{References}

Ali AB, Deuchars J, Pawelzik H, Thomson AM (1998) CA1 pyramidal to basket and bistratified cell EPSPs: dual intracellular recordings in rat hippocampal slices. J Physiol 507:201-217. CrossRef Medline

Aponte Y, Bischofberger J, Jonas P (2008) Efficient Ca2 + buffering in fastspiking basket cells of rat hippocampus. J Physiol 586:2061-2075. CrossRef Medline

Berridge MJ (1998) Neuronal calcium signaling. Neuron 21:13-26. CrossRef Medline

Buhl EH, Szilágyi T, Halasy K, Somogyi P (1996) Physiological properties of anatomically identified basket and bistratified cells in the CA1 area of the rat hippocampus in vitro. Hippocampus 6:294-305. CrossRef Medline

Callamaras N, Marchant JS, Sun XP, Parker I (1998) Activation and coordination of InsP3-mediated elementary $\mathrm{Ca} 2+$ events during global $\mathrm{Ca} 2+$ signals in Xenopus oocytes. J Physiol 509:81-91. CrossRef Medline

Carter AG, Vogt KE, Foster KA, Regehr WG (2002) Assessing the role of calcium-induced calcium release in short-term presynaptic plasticity at excitatory central synapses. J Neurosci 22:21-28. Medline

Cheng H, Lederer WJ (2008) Calcium sparks. Physiol Rev 88:1491-1545. CrossRef Medline

Cossart R, Esclapez M, Hirsch JC, Bernard C, Ben-Ari Y (1998) GluR5 kainate receptor activation in interneurons increases tonic inhibition of pyramidal cells. Nat Neurosci 1:470-478. CrossRef Medline

Dan Y, Poo MM (2004) Spike timing-dependent plasticity of neural circuits. Neuron 44:23-30. CrossRef Medline

Evstratova A, Chamberland S, Topolnik L (2011) Cell type-specific and activity-dependent dynamics of action potential-evoked Ca2 + signals in dendrites of hippocampal inhibitory interneurons. J Physiol 589:19571977. CrossRef Medline

Glickfeld LL, Scanziani M (2006) Distinct timing in the activity of cannabinoid-sensitive and cannabinoid-insensitive basket cells. Nat Neurosci 9:807-815. CrossRef Medline

Goldberg JH, Tamas G, Yuste R (2003a) Ca2 + imaging of mouse neocortical interneurone dendrites: Ia-type $\mathrm{K}+$ channels control action potential backpropagation. J Physiol 551:49-65. CrossRef Medline

Goldberg JH, Yuste R, Tamas G (2003b) Ca2 + imaging of mouse neocorti$\mathrm{cal}$ interneurone dendrites: contribution of $\mathrm{Ca} 2+$-permeable AMPA and NMDA receptors to subthreshold Ca2+ dynamics. J Physiol 551:67-78. CrossRef Medline

Goldberg JH, Tamas G, Aronov D, Yuste R (2003c) Calcium microdomains in aspiny dendrites. Neuron 40:807-821. CrossRef Medline

Goldberg JH, Lacefield CO, Yuste R (2004) Global dendritic calcium spikes in mouse layer 5 low threshold spiking interneurones: implications for control of pyramidal cell bursting. J Physiol 558:465-478. CrossRef Medline

Golding NL, Staff NP, Spruston N (2002) Dendritic spikes as a mechanism for cooperative long-term potentiation. Nature 418:326-331. CrossRef Medline 
Griguoli M, Cellot G, Cherubini E (2013) In hippocampal oriens interneurons anti-Hebbian long-term potentiation requires cholinergic signaling via $\alpha 7$ nicotinic acetylcholine receptors. J Neurosci 33:1044-1049. CrossRef Medline

Gulyás AI, Megías M, Emri Z, Freund TF (1999) Total number and ratio of excitatory and inhibitory synapses converging onto single interneurons of different types in the CA1 area of the rat hippocampus. J Neurosci 19: 10082-10097. Medline

Hertle DN, Yeckel MF (2007) Distribution of inositol-1,4,5-trisphosphate receptor isotypes and ryanodine receptor isotypes during maturation of the rat hippocampus. Neuroscience 150:625-638. CrossRef Medline

Hu H, Martina M, Jonas P (2010) Dendritic mechanisms underlying rapid synaptic activation of fast-spiking hippocampal interneurons. Science 327:52-58. CrossRef Medline

Iftinca MC, Zamponi GW (2009) Regulation of neuronal T-type calcium channels. Trends Pharmacol Sci 30:32-40. CrossRef Medline

Katona G, Kaszás A, Turi GF, Hájos N, Tamás G, Vizi ES, Rózsa B (2011) Roller Coaster Scanning reveals spontaneous triggering of dendritic spikes in CA1 interneurons. Proc Natl Acad Sci U S A 108:2148-2153. CrossRef Medline

Koester HJ, Sakmann B (1998) Calcium dynamics in single spines during coincident pre- and postsynaptic activity depend on relative timing of back-propagating action potentials and subthreshold excitatory postsynaptic potentials. Proc Natl Acad Sci U S A 95:9596-9601. CrossRef Medline

Koike M, Iino M, Ozawa S (1997) Blocking effect of 1-naphthyl acetyl spermine on $\mathrm{Ca}(2+)$-permeable AMPA receptors in cultured rat hippocampal neurons. Neurosci Res 29:27-36. CrossRef Medline

Kumar SS, Bacci A, Kharazia V, Huguenard JR (2002) A developmental switch of AMPA receptor subunits in neocortical pyramidal neurons. J Neurosci 22:3005-3015. Medline

Lacaille JC, Mueller AL, Kunkel DD, Schwartzkroin PA (1987) Local circuit interactions between oriens/alveus interneurons and CA1 pyramidal cells in hippocampal slices: electrophysiology and morphology. J Neurosci 7:1979-1993. Medline

Laezza F, Doherty JJ, Dingledine R (1999) Long-term depression in hippocampal interneurons: joint requirement for pre- and postsynaptic events. Science 285:1411-1414. CrossRef Medline

Lamsa K, Heeroma JH, Kullmann DM (2005) Hebbian LTP in feed-forward inhibitory interneurons and the temporal fidelity of input discrimination. Nat Neurosci 8:916-924. CrossRef Medline

Lamsa KP, Heeroma JH, Somogyi P, Rusakov DA, Kullmann DM (2007) Anti-Hebbian long-term potentiation in the hippocampal feedback inhibitory circuit. Science 315:1262-1266. CrossRef Medline

Le Duigou C, Kullmann DM (2011) Group I mGluR agonist-evoked longterm potentiation in hippocampal oriens interneurons. J Neurosci 31: 5777-5781. CrossRef Medline

Le Duigou C, Holden T, Kullmann DM (2011) Short- and long-term depression at glutamatergic synapses on hippocampal interneurons by group I mGluR activation. Neuropharmacology 60:748-756. CrossRef Medline

Lee SY, Földy C, Szabadics J, Soltesz I (2011) Cell-type-specific CCK2 receptor signaling underlies the cholecystokinin-mediated selective excitation of hippocampal parvalbumin-positive fast-spiking basket cells. J Neurosci 31:10993-11002. CrossRef Medline

Lei S, McBain CJ (2002) Distinct NMDA receptors provide differential modes of transmission at mossy fiber-interneuron synapses. Neuron 33: 921-933. CrossRef Medline

Le Roux N, Cabezas C, Böhm UL, Poncer JC (2013) Input-specific learning rules at excitatory synapses onto hippocampal parvalbumin-expressing interneurons. J Physiol 591:1809-1822. CrossRef Medline

Losonczy A, Magee JC (2006) Integrative properties of radial oblique dendrites in hippocampal CAl pyramidal neurons. Neuron 50:291-307. CrossRef Medline

Magee JC, Johnston D (1997) A synaptically controlled, associative signal for Hebbian plasticity in hippocampal neurons. Science 275:209-213. CrossRef Medline

Manita S, Ross WN (2009) Synaptic activation and membrane potential changes modulate the frequency of spontaneous elementary Ca2 + release events in the dendrites of pyramidal neurons. J Neurosci 29:7833-7845. CrossRef Medline

Markram H, Sakmann B (1994) Calcium transients in dendrites of neocor- tical neurons evoked by single subthreshold excitatory postsynaptic potentials via low-voltage-activated calcium channels. Proc Natl Acad Sci U S A 91:5207-5211. CrossRef Medline

Martín ED, Buño W (2003) Caffeine-mediated presynaptic long-term potentiation in hippocampal CA1 pyramidal neurons. J Neurophysiol 89: 3029-3038. CrossRef Medline

Miyazaki K, Ross WN (2013) Ca2+ Sparks and puffs are generated and interact in rat hippocampal CA1 pyramidal neuron dendrites. J Neurosci 33:17777-17788. CrossRef Medline

Miyazaki K, Manita S, Ross WN (2012) Developmental profile of localized spontaneous $\mathrm{Ca}(2+)$ release events in the dendrites of rat hippocampal pyramidal neurons. Cell Calcium 52:422-432. CrossRef Medline

Müller A, Kukley M, Stausberg P, Beck H, Müller W, Dietrich D (2005) Endogenous $\mathrm{Ca} 2+$ buffer concentration and $\mathrm{Ca} 2+$ microdomains in hippocampal neurons, J Neurosci 25:558-565. CrossRef

Nakamura T, Lasser-Ross N, Nakamura K, Ross WN (2002) Spatial segregation and interaction of calcium signalling mechanisms in rat hippocampal CA1 pyramidal neurons. J Physiol 543:465-480. CrossRef Medline

Nissen W, Szabo A, Somogyi J, Somogyi P, Lamsa KP (2010) Cell typespecific long-term plasticity at glutamatergic synapses onto hippocampal interneurons expressing either parvalbumin or CB1 cannabinoid receptor. J Neurosci 30:1337-1347. CrossRef Medline

Nyíri G, Stephenson FA, Freund TF, Somogyi P (2003) Large variability in synaptic N-methyl-D-aspartate receptor density on interneurons and a comparison with pyramidal-cell spines in the rat hippocampus. Neuroscience 119:347-363. CrossRef Medline

Okaty BW, Miller MN, Sugino K, Hempel CM, Nelson SB (2009) Transcriptional and electrophysiological maturation of neocortical fastspiking GABAergic interneurons. J Neurosci 29:7040-7052. CrossRef Medline

Oren I, Nissen W, Kullmann DM, Somogyi P, Lamsa KP (2009) Role of ionotropic glutamate receptors in long-term potentiation in rat hippocampal CA1 oriens-lacunosum moleculare interneurons. J Neurosci 29:939-950. CrossRef Medline

Péterfi Z, Urbán GM, Papp OI, Németh B, Monyer H, Szabó G, Erdélyi F, Mackie K, Freund TF, Hájos N, Katona I (2012) Endocannabinoidmediated long-term depression of afferent excitatory synapses in hippocampal pyramidal cells and GABAergic interneurons. J Neurosci 32: 14448-14463. CrossRef Medline

Regehr WG, Tank DW (1990) Postsynaptic NMDA receptor-mediated calcium accumulation in hippocampal CA1 pyramidal cell dendrites. Nature 345:807-810. CrossRef Medline

Remy S, Spruston N (2007) Dendritic spikes induce single-burst long-term potentiation. Proc Natl Acad Sci U S A 104:17192-17197. CrossRef Medline

Sambandan S, Sauer JF, Vida I, Bartos M (2010) Associative plasticity at excitatory synapses facilitates recruitment of fast-spiking interneurons in the dentate gyrus. J Neurosci 30:11826-11837. CrossRef Medline

Schiller J, Schiller Y, Stuart G, Sakmann B (1997) Calcium action potentials restricted to distal apical dendrites of rat neocortical pyramidal neurons. J Physiol 505:605-616. CrossRef Medline

Shen JB, Jiang B, Pappano AJ (2000) Comparison of L-type calcium channel blockade by nifedipine and/or cadmium in guinea pig ventricular myocytes. J Pharmacol Exp Ther 294:562-570. Medline

Sik A, Penttonen M, Ylinen A, Buzsáki G (1995) Hippocampal CA1 interneurons: an in vivo intracellular labeling study. J Neurosci 15:66516665. Medline

Simkus CR, Stricker C (2002) The contribution of intracellular calcium stores to mEPSCs recorded in layer II neurones of rat barrel cortex. J Physiol 545:521-535. CrossRef Medline

Somogyi P, Klausberger T (2005) Defined types of cortical interneurone structure space and spike timing in the hippocampus. J Physiol 562:9-26. CrossRef Medline

Szabo A, Somogyi J, Cauli B, Lambolez B, Somogyi P, Lamsa KP (2012) Calcium-permeable AMPA receptors provide a common mechanism for LTP in glutamatergic synapses of distinct hippocampal interneuron types, J Neurosci 32:6511-6516. CrossRef

Takács VT, Klausberger T, Somogyi P, Freund TF, Gulyás AI (2012) Extrinsic and local glutamatergic inputs of the rat hippocampal CA1 area differentially innervate pyramidal cells and interneurons. Hippocampus 22: 1379-1391. CrossRef Medline 
Thiagarajan TC, Lindskog M, Tsien RW (2005) Adaptation to synaptic inactivity in hippocampal neurons. Neuron 47:725-737. CrossRef Medline

Topolnik L, Azzi M, Morin F, Kougioumoutzakis A, Lacaille JC (2006) mGluR1/5 subtype-specific calcium signalling and induction of longterm potentiation in rat hippocampal oriens/alveus interneurones. J Physiol 575:115-131. CrossRef Medline

Topolnik L, Chamberland S, Pelletier JG, Ran I, Lacaille JC (2009) Activitydependent compartmentalized regulation of dendritic $\mathrm{Ca} 2+$ signaling in hippocampal interneurons. J Neurosci 29:4658-4663. CrossRef Medline

Tóth K, McBain CJ (1998) Afferent-specific innervation of two distinct AMPA receptor subtypes on single hippocampal interneurons, Nat Neurosci 1:572-578.

Tsay D, Dudman JT, Siegelbaum SA (2007) HCN1 channels constrain synaptically evoked $\mathrm{Ca} 2+$ spikes in distal dendrites of CA1 pyramidal neurons. Neuron 56:1076-1089. CrossRef Medline van Hooft JA, Giuffrida R, Blatow M, Monyer H (2000) Differential expression of group I metabotropic glutamate receptors in functionally distinct hippocampal interneurons. J Neurosci 20:3544-3551. Medline

Wang SS, Denk W, Häusser M (2000) Coincidence detection in single dendritic spines mediated by calcium release. Nat Neurosci 3:1266-1273. CrossRef Medline

Watanabe S, Hong M, Lasser-Ross N, Ross WN (2006) Modulation of calcium wave propagation in the dendrites and to the soma of rat hippocampal pyramidal neurons. J Physiol 575:455-468. CrossRef Medline

Wei DS, Mei YA, Bagal A, Kao JP, Thompson SM, Tang CM (2001) Compartmentalized and binary behavior of terminal dendrites in hippocampal pyramidal neurons. Science 293:2272-2275. CrossRef Medline 